\title{
The Danish health care system and epidemiological research: from health care contacts to database records
}

This article was published in the following Dove Press journal:

Clinical Epidemiology

\author{
Morten Schmidt ${ }^{1,2}$ \\ Sigrun Alba Johannesdottir \\ Schmidt ${ }^{1,3}$ \\ Kasper Adelborg ${ }^{1,4}$ \\ Jens Sundbøll' \\ Kristina Laugesen' \\ Vera Ehrenstein' \\ Henrik Toft Sørensen' \\ 'Department of Clinical Epidemiology, \\ Aarhus University Hospital, Aarhus, \\ Denmark; ${ }^{2}$ Department of Cardiology, \\ Regional Hospital West Jutland, Herning, \\ Denmark; ${ }^{3}$ Department of Dermatology, \\ Aarhus University Hospital, Aarhus, \\ Denmark; ${ }^{4}$ Department of Clinical \\ Biochemistry, Aarhus University Hospital, \\ Aarhus, Denmark
}

\begin{abstract}
Denmark has a large network of population-based medical databases, which routinely collect high-quality data as a by-product of health care provision. The Danish medical databases include administrative, health, and clinical quality databases. Understanding the full research potential of these data sources requires insight into the underlying health care system. This review describes key elements of the Danish health care system from planning and delivery to record generation. First, it presents the history of the health care system, its overall organization and financing. Second, it details delivery of primary, hospital, psychiatric, and elderly care. Third, the path from a health care contact to a database record is followed. Finally, an overview of the available data sources is presented. This review discusses the data quality of each type of medical database and describes the relative technical ease and cost-effectiveness of exact individual-level linkage among them. It is shown, from an epidemiological point of view, how Denmark's population represents an open dynamic cohort with complete long-term follow-up, censored only at emigration or death. It is concluded that Denmark's constellation of universal health care, long-standing routine registration of most health and life events, and the possibility of exact individual-level data linkage provides unlimited possibilities for epidemiological research.
\end{abstract}

Keywords: health care sector, political systems, population health, registries, epidemiology

\section{Introduction}

Denmark has a large network of population-based medical databases containing routinely collected data, covering many aspects of life and health. ${ }^{1}$ To fully grasp the potential of these data for research, and to properly interpret studies based on these resources, one must consider the underlying health care system and the pathway from the point of health service to a database record.

Three qualities make Denmark "an epidemiologist's dream": ${ }^{1}$ 1) its universal tax-funded health care system with residency-based entitlement; 2) availability of government-maintained nationwide registries, providing longitudinal sources of routinely collected administrative, health, and clinical quality data; and 3) the unique personal identifier assigned to every Danish resident, enabling exact individual-level linkage of all records and lifelong follow-up. In epidemiological terms, the population of Denmark is an open cohort with known dates of entry and exit, and with various types of rich health data recorded between those dates. ${ }^{1}$
Correspondence: Morten Schmidt Department of Clinical Epidemiology, Aarhus University Hospital, Olof Palmes Allé 43-45, 8200 Aarhus N, Denmark Email morten.schmidt@clin.au.dk 
Table I The Danish health care system from health care planning and delivery to data registration: an outline of the present review

\begin{tabular}{|c|c|}
\hline Perspectives & Review sections \\
\hline Health care planning (macro perspective) & $\begin{array}{l}\text { - History of the Danish health care system } \\
\text { - Organization of the Danish health care system } \\
\circ \text { State } \\
\circ \text { Regions } \\
\circ \text { Municipalities } \\
\circ \text { Private health care } \\
\text { - Financing of the Danish health care system } \\
\circ \text { Taxation } \\
\circ \text { Administration } \\
\circ \text { Public health insurance } \\
\circ \text { Medicine costs }\end{array}$ \\
\hline Health care delivery (micro perspective) & $\begin{array}{l}\text { - Danish health care delivery systems } \\
\circ \text { Primary care } \\
\circ \text { Hospital care } \\
\circ \text { Mental health care } \\
\circ \text { Elderly care }\end{array}$ \\
\hline Health care registration (research perspective) & $\begin{array}{l}\text { - Danish health care data } \\
\circ \text { Digital health } \\
\circ \text { Data regulation } \\
\circ \text { Data linkage and follow-up } \\
\text { - Danish medical databases } \\
\circ \text { Administrative databases } \\
\circ \text { Health databases } \\
\circ \text { Clinical quality databases } \\
\circ \text { Data not available } \\
\text { - Data quality } \\
\circ \text { Validity } \\
\circ \text { Completeness } \\
\text { - Danish health statistics }\end{array}$ \\
\hline
\end{tabular}

In this review (outlined in Table 1), we present the key elements of the Danish health care system - from planning and delivery to data registration. First, we present the history, the overall organization, and the financing of health care in Denmark. Second, we detail delivery of primary, hospital, psychiatric, and elderly care. Third, we follow the path from a health care contact to a database record and show how the Danish health care system provides a framework supporting the use of such records for epidemiological research and health care statistics.

\section{History of the Danish health care system}

Denmark has a long tradition of public welfare, including provision of health services. Recent decades have brought about gradual changes in the structure of the Danish health care system, best subdivided into the periods before, between, and after the government reforms of 1970 and $2007 .^{2}$ Before 1970, all Danish hospitals were owned by either Municipalities or Counties. Services provided by general practitioners (GPs) and specialists in private practice were funded by mandatory sickness funds, while hospital care was funded by local and federal taxes. ${ }^{2}$

The local government reform of 1970 established the current organization of the Danish health care system. ${ }^{2}$ Counties became exclusive owners of hospitals, with attendant responsibilities; the health care system became almost entirely tax-funded; and the sickness fund system was abolished. ${ }^{3}$ In the 2007 reform of the Danish public sector, ${ }^{4}$ the number of Municipalities was substantially reduced, while five large Regions replaced the 14 Counties as the main administrative units (Figure 1). The Regions are defined geographically as the North Denmark Region ( $\sim .6$ million), the Central Denmark Region ( 1.3 million), the Region of Southern Denmark ( 1.2 


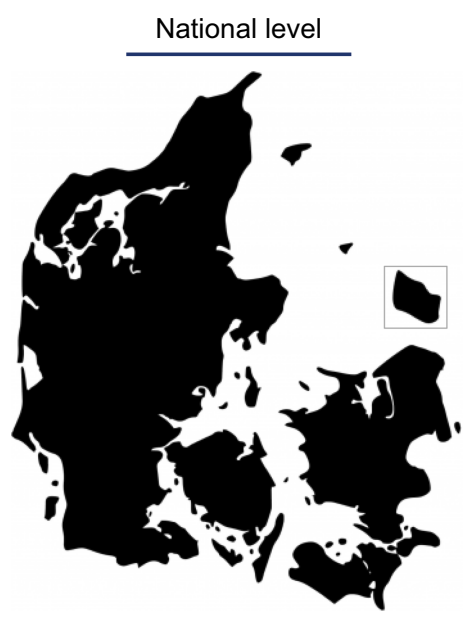

Ministry of Health

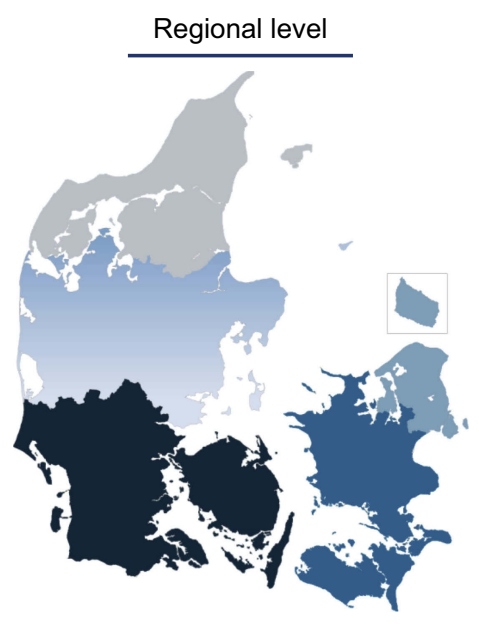

5 Regions

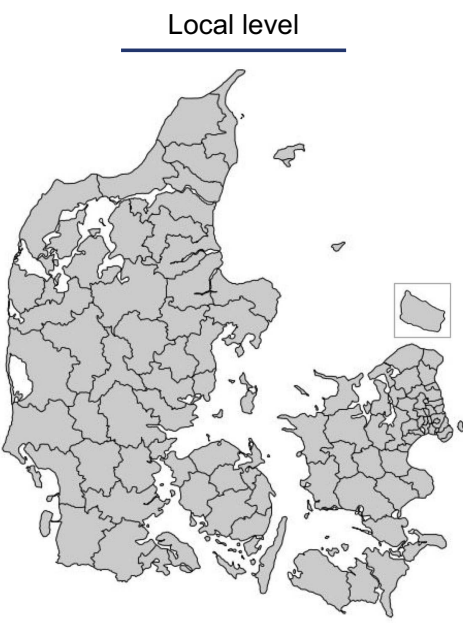

98 Municipalities

Figure I The three administrative levels of the Danish health care system. Ministry of Health (modified). ${ }^{5}$

million), the Region Zealand ( $\sim 0.8$ million), and the Capital Region of Denmark (population $\sim 1.8$ million). The five Regions have, since their establishment, had the primary responsibility for overseeing somatic and psychiatric hospitals, GPs, and specialists in private practice.

Following the 2007 reform, Denmark has invested substantially in its hospital system by extending and renovating existing hospitals and building new and larger facilities (Figure 2). ${ }^{4}$ There has been a simultaneous shift towards centralization, with fewer acute hospitals, closure of several small hospitals, and expansion of outpatient hospital care. Reforms have involved economic incentives to increase hospital productivity as measured by diagnosisrelated groups, establishment of clinical programs to improve quality of care and patient safety, and implementation of electronic patient records. In addition, use of private hospital services has increased to adhere to government-mandated maximum waiting time guarantees.

\section{Organization of the Danish health care system}

The Danish welfare model promotes society-wide health and social equity through tax-financed services, including universal health care, education, student aid, disability pensions, and unemployment insurance. ${ }^{3}$ The health care system is currently organized into three administrative levels (Figure 1): the national level (State), the regional level (5 Regions), and the local level (98 Municipalities). Elections are held separately for the national parliament at intervals of up to 4 years and for regional and municipal councils at exact 4-year intervals. In addition, Denmark also has a small private health care sector.

\section{State}

The government, headed by the Ministry of Health, is responsible for defining the framework of the Danish health care system. Thus, the Ministry of Health plays a steering role at the national level by passing health legislation, issuing national guidelines, protecting patients' rights, conducting audits, and monitoring health care professionals, hospitals, and pharmacies. The Ministry of Health acts through various subordinate agencies, as described in Table $2 .^{5}$

Pharmacies are privately operated, but subject to state regulation. The Ministry of Health and the Danish Medicines Agency control the sector through a licensing system, which determines the number of pharmacies and their locations. The proprietor pharmacist owns his/her pharmacy and is economically responsible for its financing and operation, and may start up to seven branch pharmacies within $75 \mathrm{~km}$ from the main pharmacy. As of September 2017, the Danish community pharmacy sector consisted of 237 private community pharmacies. In addition, there were 202 branch pharmacies, 48 pharmacy outlets, and approximately 500 over-the-counter outlets and 350 medicine delivery facilities, all of which are affiliated with one of the pharmacies. $^{6}$

\section{Regions}

The Regions govern primary and secondary health care services, provided by GPs, hospitals, and specialists in private practice (Figure 3 ). ${ }^{5}$ The Regions also administer the drug reimbursement plan, based on data electronically collected by community pharmacies when prescriptions 


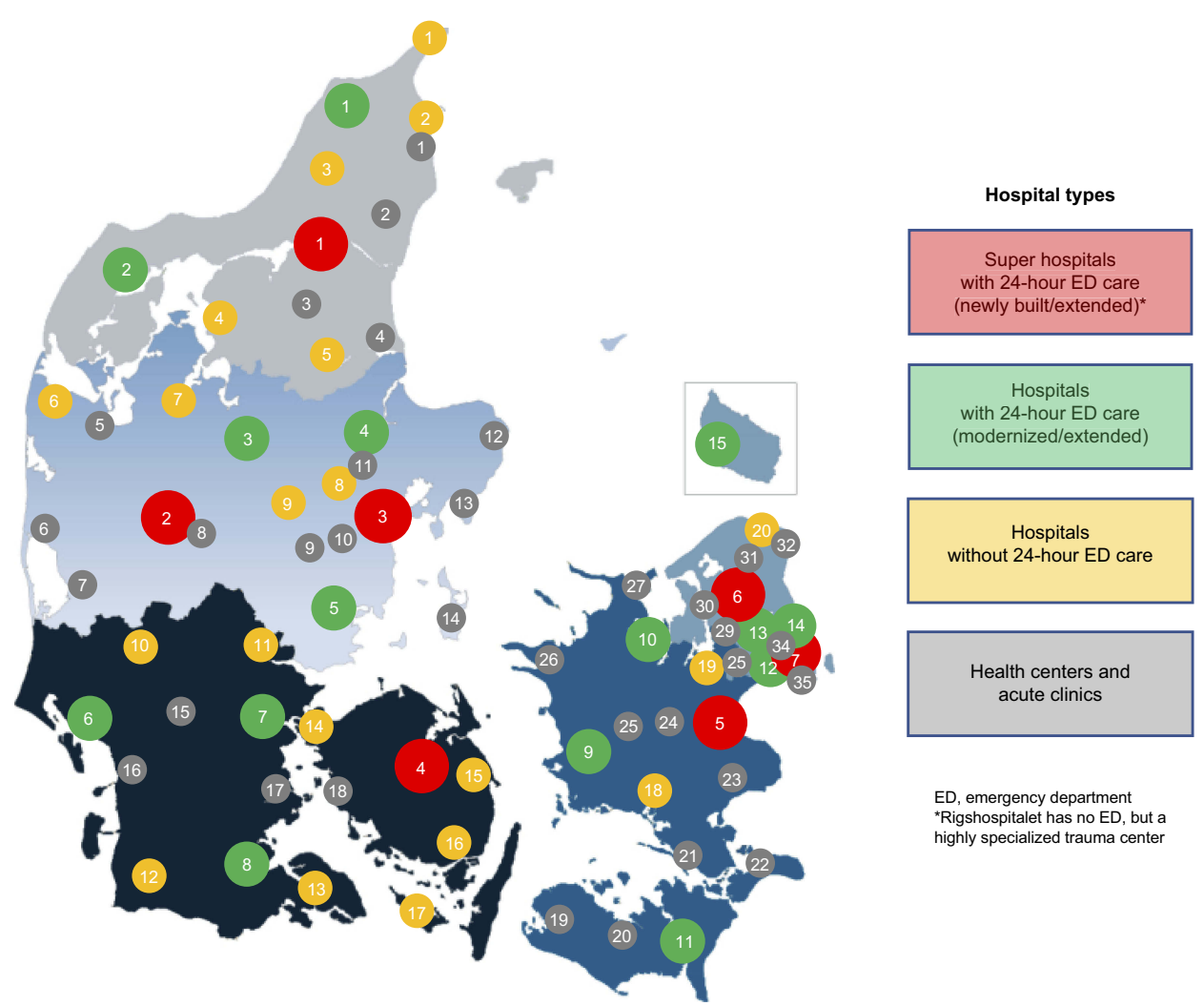

Cities listed according to region: North Denmark Region; Central Denmark Region; Region of Southern Denmark; Region Zealand; Capital Region of Denmark.

(1) Aalborg; (2) Gødstrup, (3) Aarhus; (4) Odense; (5) Køge; (6) Favrholm, (7) Copenhagen (Rigshospitalet).

(1) Hjørring, (2) Thisted; (3) Viborg, (4) Randers, (5) Horsens; (6) Esbjerg, (7) Kolding, (8) Aabenraa; (9) Slagelse, (10) Holbæk, (11) Nykøbing Falster; (12) Hvidovre, (13) Herlev-Gentofte, (14) Bisbebjerg, (15) Rønne. (1) Skagen, (2) Frederikshavn, (3) Brønderslev, (4) Farsø, (5) Hobro; (6) Lemvig, (7) Skive, (8) Hammel, (9) Silkeborg; (10) Grindsted, (11) Vejle, (12) Tønder, (13) Sønderborg, (14) Middelfart, (15) Nyborg, (16) Svendborg, (17) ÆErø; (18) Næstved, (19) Roskilde; (20) Hornbæk.

(1) Sæby, (2) Dronninglund, (3) Støvring, (4) Hadsund; (5) Struer, (6) Ringkøbing, (7) Tarm, (8) Ikast, (9) Brædstrup, (10) Skanderborg, (11) Hadsten, (12) Grenaa, (13) Ebeltoft, (14) Samsø; (15) Brørup, (16) Ribe, (17) Haderslev, (18) Assens; (19) Nakskov, (20) Maribo, (21) Vordingborg, (22) Stege, (23) Faxe, (24) Ringsted, (25) Sorø, (26) Kalundborg, (27) Odsherred; (28) Tåstrup, (29) Egedal (30), Frederikssund, (31) Fredensborg, (32) Helsingør, (34) Frederiksberg / Rødovre / Lyngby, (35) Tårnby / Amager.

Figure 2 The hospital landscape in Denmark.

are dispensed. Although pharmacies operate privately, they are regulated by the government.

Public hospitals (somatic and psychiatric) and local community mental health centers are owned and operated by the Regions. Private hospitals have also provided certain services to the Regions since 2002, under the policy of "extended free choice of hospital". According to this policy, residents in need of hospital care may choose, within certain limits, among all public or private hospitals. Thus, if a Region cannot ensure diagnostic examination within 30 days of referral, patients have the right to examination at a private hospital in Denmark or at a hospital abroad (the latter is subject to approval by the Danish Health Authority). If, for medical reasons, it is not possible to provide a diagnosis within 1 month, at a minimum, a patient must receive a detailed plan for further investigation of the presenting health problem. If, for lack of capacity, a Region is unable to provide a diagnostic assessment within 30 days, the "extended free choice of hospital" policy applies. Patients with life-threatening diseases may be referred by the Regions for experimental treatment in private hospitals in Denmark or abroad, if such treatment is not available in public hospitals. In accordance with European Union Regulations on the coordination of social security systems and cross-border health care, Danish residents have the right to be reimbursed for the costs of health care provided in other European Union/European Economic Area Member States. ${ }^{5}$

GPs practice privately and work according to a collective agreement, subject to periodic renegotiations between the government and the physicians' union. Remuneration is based on a combination of capitation (based on patient lists) and fee-for-service. Specialists in private practice are also self-employed and are reimbursed for the mandated health services on a fee-forservice basis. ${ }^{5}$ 
Table 2 Danish health care authorities and their responsibilities

\begin{tabular}{|c|c|}
\hline Authority & Area of responsibility \\
\hline Ministry of Health & $\begin{array}{l}\text { - Defines the framework of the national health care system and acts through the subordinate agencies } \\
\text { below }\end{array}$ \\
\hline Danish Health Authority & $\begin{array}{l}\text { - Main health authority } \\
\text { - Advises the Ministry of Health and other public institutions at the national, regional, and local adminis- } \\
\text { trative levels } \\
\text { - Promotes public health policies for preventing and treating disease, eg, through national clinical guidelines } \\
\text { - Responsible for health planning, including education of sufficient numbers of health care professionals }\end{array}$ \\
\hline Danish Medicines Agency & $\begin{array}{l}\text { - Approves new drugs } \\
\text { - Inspects pharmaceutical companies and pharmacies } \\
\text { - Monitors side-effects and adverse events related to drugs and devices } \\
\text { - Authorizes clinical trials } \\
\text { - Decides which drugs qualify for partial reimbursement }\end{array}$ \\
\hline Danish Patient Safety Authority & $\begin{array}{l}\text { - Protects patients' rights and safety } \\
\text { - Inspects health institutions and staff, and issues authorizations to health care professionals } \\
\text { - Administers the reporting system for adverse events } \\
\text { - Provides feedback and information to the Regions and Municipalities regarding specific risk situations } \\
\text { - Provides permissions to access medical records for specific research projects }\end{array}$ \\
\hline $\begin{array}{l}\text { Danish Agency for Patient } \\
\text { Complaints }\end{array}$ & $\begin{array}{l}\text { - Handles complaints about treatment and infringement of patients' rights } \\
\text { - Provides no economic compensation }\end{array}$ \\
\hline Danish Health Data Authority & $\begin{array}{l}\text { - Provides systematic health data on volume of activity, economics, and quality of care for patients, health } \\
\text { care professionals, researchers, and administrative staff } \\
\text { - Maintains a wide range of medical databases } \\
\text { - Sets national standards for digitization and data security, promotes coherent IT architecture within the } \\
\text { health care system, and ensures availability of relevant and valid health data to benefit patient treatment } \\
\text { and research }\end{array}$ \\
\hline State Serum Institute & $\begin{array}{l}\text { - Responsible for the surveillance, prevention, and control of infectious diseases, congenital disorders, and } \\
\text { biological threats } \\
\text { - Oversees the supply of vaccines, other biological products, advanced diagnostics of infectious diseases, and } \\
\text { contingency plans for bioterrorism } \\
\text { - Research, including administration of the national biobank }\end{array}$ \\
\hline Danish Ethical Council & $\begin{array}{l}\text { - Advises the parliament and public authorities on ethical issues regarding new technologies that affect } \\
\text { human lives } \\
\text { - Facilitates debate on such matters as the potential consequences of new biotechnologies and gene } \\
\text { technologies }\end{array}$ \\
\hline $\begin{array}{l}\text { National Committee on Health } \\
\text { Research Ethics }\end{array}$ & $\begin{array}{l}\text { - Ensures that health research projects are carried out in an ethically responsible manner, balancing the } \\
\text { rights, safety, and well-being of persons enrolled in clinical trials and other research against the need for } \\
\text { developing valuable new knowledge } \\
\text { - Coordinates the work of the regional scientific ethical committees and functions as a court of appeal for } \\
\text { research projects rejected by a regional committee } \\
\text { - Provides statements and guidelines on general issues not tied to a specific research project }\end{array}$ \\
\hline
\end{tabular}

\section{Municipalities}

A special national funding scheme (social financing agreement) ensures provision of certain health services for disadvantaged resident groups, such as recipients of welfare benefits and the elderly. Otherwise, implementation and delivery of health care services are largely decentralized on the regional or municipal levels. Municipalities are responsible for social and community care, including welfare allowances (eg, disability pensions), home care, elderly care, housing for the mentally disabled and homeless, care for mentally or 


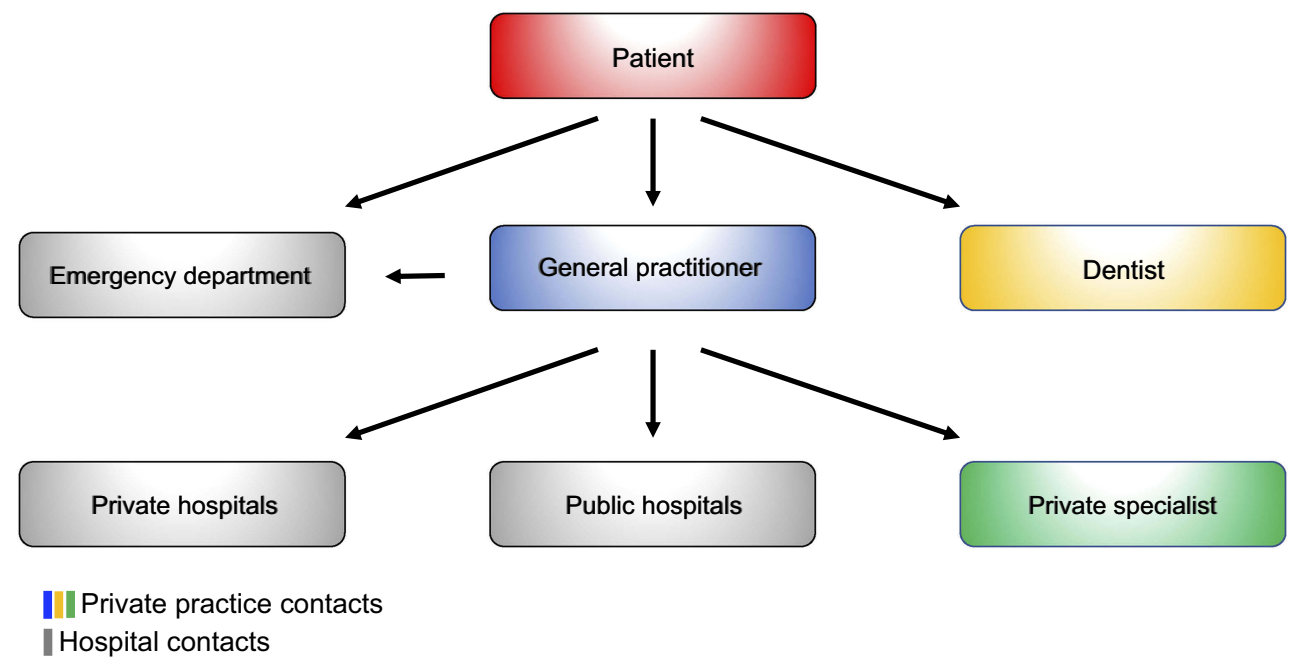

Figure 3 Access structure of the Danish health care system. Except for emergency and dental care, general practitioners are the first point of contact for patients in the Danish health care system. General practitioners thereby act as gatekeepers to secondary care, including referrals to hospitals and office-based private specialists.

physically disabled persons, as well as substance abuse and addiction treatment. Municipalities also provide a wide range of primary and preventive services, including prenatal and postnatal home visits, rehabilitation, school health services, and pediatric dental care. ${ }^{5}$

Although primary prevention programs at the local level are not mandated by law, Municipalities are responsible for ensuring that local communities provide healthy environments, activities, and facilities that promote well-being and prevent disease. Because Municipalities cofinance treatment provided by hospitals and GPs, they have an economic incentive to implement effective disease-prevention and health-promotion programs. ${ }^{5}$

\section{Private health care}

Private hospitals account for less than $1 \%$ of hospital beds in Denmark. Only a small percentage of health care services are delivered by private providers without a reimbursement contract with the National Health Service. Reasons for using private hospitals and clinics include faster access to diagnostic procedures or treatment and a desire for treatments not covered by public health insurance (eg, fertility treatment beyond the first child and most cosmetic surgery). The three ways to access private hospitals and clinics are self-payment, private health insurance, and via a public subsidy under the "extended free choice of hospital" scheme described above. ${ }^{5}$

Private health insurance typically covers services not covered or only partially covered by the national health care system. Also, many Danish employers offer private health insurance as an employment benefit. The non-profit organization "Health Insurance Denmark" ("Sygeforsikringen Danmark") is a common source of private insurance policies. Although $40 \%$ of the population is covered by private health insurance, it accounts for less than $2 \%$ of total health care expenditures. ${ }^{7}$

\section{Financing of the Danish health care system Taxation}

All residents contribute to the financing of the health care system through federal and local taxation, and may not opt out, though certain expenses are deductible. Tax revenue finances $84 \%$ of the total health care expenditure (approximately $8.9 \%$ of the gross domestic product). ${ }^{5}$ Out-of-pocket copayments are moderate compared with other European countries, ${ }^{8}$ amounting to $16 \%$ of health care expenditures (1.7\% of the gross domestic product), mainly through contributions to the costs of medications (detailed below under "Medicines"), prescribed physiotherapy (60\% copayment), glasses (for children $<16$ years and senior citizens), and dental care. Dental care is free until age 18, after which most treatment costs are self-covered. Still, public funding is provided to help defray the costs of dental examinations, preventive treatments, treatment of caries, periodontal disease, root decay, and tooth extractions.

In 2014, total health care expenditures in Denmark accounted for $10.6 \%$ of the gross domestic product, which is slightly higher than the average expenditure $(9.0 \%)$ in the countries within the Organization for Economic Cooperation and Development. ${ }^{5}$ The 
expenditure for care of the elderly and disabled accounted in the same year for about $2.8 \%$ of the gross domestic product, and total per capita spending was $\$ 4,906{ }^{8}$

\section{Administration}

The economic framework for the Danish health care system is set at the national level and administered through block grants, reimbursements, and equalization schemes. As part of the annual national budget, a financial agreement is made between the national, regional, and municipal administrative levels. Each Region has the mandate to regulate and balance its services and needs. Regions and Municipalities are obliged to meet their budget with a $1.5 \%$ margin. Meeting budget targets has traditionally required productivity increases. ${ }^{5}$

The Regions are funded through a block grant (75\%), as well as activity-based subsidies from both the national government and the Municipalities. Municipalities themselves are financed by a block grant from government and by local taxes. Government block grants take into account regional variation, including demographic differences. Similarly, the activity-based subsidies are based on hospital activity, accounting for patient numbers and characteristics (diagnoses, treatments, and demographics). The amount of the Municipal activity-based subsidy depends on the extent to which residents utilize regional health care services (eg, hospital and GP services). Successful disease prevention and health promotion provided by the Municipalities contribute to a decreased need for subsidies and, thus, to cost savings. ${ }^{5}$

\section{Public health insurance}

At the individual level, each Danish resident must choose between Group 1 and Group 2 membership in public health insurance. Group 1 members ( $>99 \%$ of the population) are registered with a specific GP, who provides primary care and referral to secondary care free of charge. Patients may selfrefer to certain specialists, such as ophthalmologists, otolaryngologists, dentists, and chiropractors. Group 2 members may choose freely among GPs, dentists, chiropractors, and all private specialists without referral (except for physiotherapists, podiatrists, and psychologists), subject to copayment. For both Group 1 and Group 2 members, hospital treatment requires referral, but is free of charge. ${ }^{3}$

\section{Medicines}

Pharmaceutical companies are free to set official prices for their products. However, members of the Danish Association of the Pharmaceutical Industry are subject to a price-cap agreement between the Association, the Ministry of Health, and the Danish Regions. Procurement and pricing procedures differ between the primary and secondary health care sectors. At public hospitals, 99\% of all medicines are purchased through the pharmaceutical procurement service Amgros, owned by the Regions. ${ }^{9}$ The Regions pay for all medicines used at hospitals, so that admitted patients receive them free of charge. In the primary health care sector, pricing of medicines varies among competing products, but for a given product prices are the same nationwide, ensuring price transparency. ${ }^{5}$

While medicines used during treatment at public hospitals are provided without cost to patients, patient copayments are required for prescriptions redeemed at community pharmacies. $^{10}$ A central authority (Reimbursement Committee) decides whether costs of a particular medicine are partially reimbursable to patients. There are two different types of reimbursement schemes: general reimbursement, covering all residents automatically (although for some drugs reimbursement requires specification of an indication); and individual reimbursement, awarded on a case-by-case basis. $^{10}$ All medicines under the general reimbursement scheme are tax-financed. According to this scheme, the percentage of costs reimbursed increases with an individual's total expenditures for reimbursable medicines during the most recent 365 days. As of 2018, the first $\$ 150$ is paid in full by the patient (except for children, whose parents immediately receive a $60 \%$ reimbursement). ${ }^{11}$ Subsequent reimbursements increase in steps of $50 \%, 75 \%$, and $85 \%$, until out-of-pocket expenditures are capped at about $\$ 600 .^{11}$

\section{Danish health care delivery systems}

The different levels of health care at the point of delivery include primary, hospital, psychiatric, and elderly care, as described below.

\section{Primary care}

Primary health care services are provided by GPs, other health care professionals in private practice (eg, dentists, physiotherapists, and psychologists), and Danish Municipalities, as noted above. Primary health care providers contract with and are reimbursed by the National Health Service. ${ }^{12}$

\section{General practitioners}

GPs are generalists with the prerequisite skills to evaluate patients' need for referral to specialists. GPs are assisted by hospital-based diagnostic support, including laboratory services and diagnostic imaging. All Danish residents have the right to be listed with a GP of their choice, and $>99 \%$ 
are included in such lists (ie, Group 1 members). GPs are obligated to serve the patients who have registered with them, averaging 1,600 patients per GP. Although many GPs have a solo practice, an increasing proportion has been joining group practices. ${ }^{12}$

Except in emergencies, Denmark's approximately 3,600 GPs ( $20 \%$ of the physician workforce) are the first point of contact for patients (Figure 3). GPs, thus, fill a key position in the Danish health care system, acting as gatekeepers to secondary (specialized) care, including referrals to office-based specialists and inpatient and outpatient hospital care. GPs also refer patients to municipal services for rehabilitation and home care. Primary care outside regular office hours is covered via a rotation system among GPs in a given geographical area. One exception is the Capital Region, which, since 2014, has had its own coverage system ("1813" pronounced: "eighteen-thirteen", named after the emergency number), which is operated by nurses under the supervision of physicians. ${ }^{12}$

\section{Home nursing}

Home nurses provide care and treatment to patients who are acutely ill, chronically ill, or dying. Nurses are responsible for enabling patients to stay in their homes or close to home for as long as possible. All patients are entitled to home nursing free of charge, if prescribed by a physician. Also, the Municipalities are required to provide all necessary aids and appliances free of charge.

Some Municipalities have set up special residential units for short-term stays with intensive treatment by trained nurses for patients who do not require hospitalization but are temporarily unable to stay in their own homes. In addition, there are 19 adult hospices and one children's hospice in Denmark, which care for incurably sick and dying patients. ${ }^{5}$

\section{Rehabilitation}

Rehabilitation includes physical and cognitive training to restore the ability to carry out self-care and other activities of daily living. It includes patient education and training for reemployment. Rehabilitation efforts may start in the inpatient setting. At discharge, the hospital prepares a rehabilitation plan, describing the patient's current functional level and rehabilitation needs. The hospital forwards the plan to both the Municipality and the patient's GP, passing on responsibility for rehabilitation from the Region to the Municipality. ${ }^{5}$

\section{Health checkups for children}

All women who have given birth and their families receive regular home visits from a health visitor free of charge.
Typically, health visitors are specially trained nurses. They track the child's height and weight, provide parenting support and help with breastfeeding, and give general health advice. Health visitors work closely with midwives, nurses, and GPs. ${ }^{5}$

All children receive preventive health checkups at their GP's office at ages 5 weeks, 5 months, 1 year, and annually thereafter until age 5 . The examinations follow a set structure prescribed by the Danish Health Authority. ${ }^{13}$ The GP evaluates the child's physical and mental health, growth, and general development, to identify or prevent health problems.

All Danish schoolchildren are entitled to school-based health checkups, conducted by health visitors and/or physicians. These regular checkups include assessment of height and weight, screening for vision and hearing abnormalities, physical and psychiatric symptoms, linguistic skills, sleeping/eating habits, social competencies, and general development. Upon reaching age 18 years, Danish men must appear before the Danish Draft Board to assess their fitness for military service. This assessment includes a detailed physical examination and a cognitive test. ${ }^{14}$

\section{Vaccinations}

The national childhood immunization program provides vaccines for children free of charge.

These include vaccines against pneumococcal disease (PCV 7), whooping cough, diphtheria, tetanus, polio, measles, German measles, mumps, Haemophilus influenzae type B, and human papilloma virus (currently Gardasil 9). Several other vaccines are available to high-risk groups, such as influenza vaccine for persons with certain chronic diseases or those older than 65 years. Routine vaccinations within the national immunization programs are paid for by the Regions, while vaccinations needed for, eg, vacations are not. ${ }^{5}$ For diphtheria, tetanus, and whooping cough, childhood immunization coverage is $>90 \%$ in Denmark.

\section{Hospital care}

Each Region is responsible for providing hospital treatment to its residents, and emergency treatment to all persons in need. Of treatments provided in hospitals, $90 \%$ are considered standard and $10 \%$ are specialized. Standard treatments are usually provided at a hospital in the patient's region of residence. Definitions of specialized treatments are based on the size of the affected patient group and the complexity and cost of needed services. 
Specialized treatments are categorized as regional functions (available in one to three hospitals per Region) or national (available only in one to three hospitals in the country). ${ }^{5}$

Between 2007 and 2020, highly specialized hospitals are expected to reduce the number of bed-days by $20 \%$ and to expand outpatient treatment by $50 \% .^{5}$ The emergency health care service is currently being restructured: 40 emergency departments have been merged into 21 larger units, staffed with specialists on a 24-hour basis (Figure 2). Pre-hospital emergency care is provided by paramedics, nurses, and doctors on the scene, in ambulances, or in especially equipped helicopters. ${ }^{5}$

\section{Mental health care}

Mental health care in Denmark has undergone considerable change during the last decades, marked by an increase in outpatient treatment and a reduction in the number of hospital beds. Community mental health centers provide outpatient treatment and extensive crisis support. While patients are not admitted, they may stay at a center until their condition improves or until a psychiatric diagnosis and treatment plan are available. ${ }^{5}$

In May 2015, the Danish Mental Health Act was amended with the aim of improving treatment for people with mental illness, including reduced use of coercive measures such as physical restraint. To ensure careful use of necessary coercive measures and limit the duration of restraint, the new rules stipulate a minimum frequency of medical supervision and continuous assessment of the ongoing need for restraint. ${ }^{5}$

\section{Elderly care}

Like many Western countries, Denmark has a growing elderly population, both in absolute numbers and relative to the total population. It is estimated that the number of persons older than 80 years will double by $2040 .^{5}$ The age of eligibility for a state pension in Denmark has shifted upwards several times, in line with increased life expectancy. It is planned that the age of eligibility will increase again from the current 65 years to 67 years during 20192022 , and to 68 years in $2030 .^{5}$ To meet the challenges of an aging population, Danish policy aims to promote and extend the independence of elderly people, ensuring their continued self-sufficiency and well-being. The Municipalities achieve this goal through prevention and rehabilitation programs, and by providing free-of-charge home care services and nursing facilities. All Municipalities must establish Senior Citizens' Councils to obtain client input. Council members must be above the age of 60 years and are elected for 4-year terms. Each Municipality must consult with its Senior Citizens Council regarding all issues relevant to its elderly population. ${ }^{5}$

Home care services are targeted at elderly people who live at home but are unable to manage everyday life on their own. Home care falls into two categories: practical help (eg, cleaning and laundering) and personal care (eg, bathing and shaving). In 2015, 12\% of all persons over 65 years received home care services. While elderly people pay for food services, copayment cost may not exceed the average production cost. Self-reliance is a fundamental principle of home care services. Municipalities are required by law to assess whether a person in need of home care services could benefit from rehabilitation. ${ }^{5}$

Municipalities must provide preventive home visits to physically and socially vulnerable persons aged 65-79 years, whenever needed, and annual visits to all persons over 80 years. The purpose of these visits is to identify any need for individual assistance and to evaluate each elderly person's well-being and current life situation. ${ }^{5}$ Municipalities are responsible for determining whether an elderly person should be offered the opportunity to move to a nursing home, providing extensive specialized care for those who no longer have full physical or mental faculties. In 2015, approximately $4 \%$ of persons over age 65 years lived in nursing homes in Denmark. Nursing home facilities are staffed around the clock by health care professionals. Residents pay individually for their room, food, and private expenses, while nursing and health care services are provided free of charge. The waiting time for a standard place in a nursing home must not exceed 2 months following referral. ${ }^{5}$

\section{Danish health care data Digital health}

Denmark is an international pacesetter in digital health and ranks as number one regarding IT systems in hospitals and general practice, as well as digital communication among health care sectors. ${ }^{5}$ Increasing use of common IT standards facilitates electronic communication among all health care providers - including hospitals, GPs, specialists, laboratories, local authorities, and home care services. For example, all GPs maintain electronic health records and nearly all GPs use them to 
exchange records $(98 \%)$, to order prescriptions at pharmacies $(99 \%)$, to receive laboratory test results from hospitals $(100 \%)$, and to send referrals to hospitals (97\%), medical specialist clinics (100\%), and psychologists $(100 \%) .^{5}$

Many Danish digital solutions have won international acclaim (Table 3). ${ }^{5}$ Denmark, thus, has a solid foundation for further digitization of the health care system. A new national strategy for "digital health" has been launched to advance sustainable development of the Danish health care system. ${ }^{15}$ The strategy includes 27 initiatives within five main areas: engaging citizens as active partners; ensuring timely knowledge exchange; developing the field of population health and prevention; providing excellent data security to win trust; and implementing a flexible digital health care infrastructure. ${ }^{15}$ Besides increasing the efficacy of health care delivery, the information recorded and collected during digitized workflows feeds on a daily basis into Danish population-based data sources.

\section{Data regulation}

As part of a reform entitled "visibility of results", a Health Data Program was established in 2014 to create "better health care through better use of data". Danish regulations make electronic health care data accessible for clinical trials and other research projects, if the following basic requirements are met: demonstrated importance to society; lawful, secure, and safe handling and use of data; and respect for individuals' right to privacy. Approval from an Ethics Committee may be needed to conduct research. The Danish Data Protection Agency safeguards that legal requirements bearing on research are followed.

\section{Data linkage and follow-up}

A key feature facilitating use of Danish registries and databases for research is the possibility of technically simple, cost-effective, and exact individual-level record linkage among all data sources. Linkage is achieved using a unique 10-digit personal identifier [Central Personal Register (CPR) number], ${ }^{16}$ assigned at birth or upon immigration by the Danish Civil Registration System to all persons residing in Denmark. Use of the Danish Civil Registration System as a research tool has been described in detail previously; ${ }^{16}$ one of its major strengths is the possibility of lifelong follow-up with accurate censoring at emigration or death. ${ }^{16}$

Table 3 Key IT solutions within the Danish health care system

\begin{tabular}{|c|c|}
\hline IT solution & Description \\
\hline MedCom3 system & Digitizes much of the communication within the health system. \\
\hline Health data network & Secures electronic communication among all health care providers. \\
\hline $\begin{array}{l}\text { National e-health } \\
\text { portal }\end{array}$ & $\begin{array}{l}\text { A National health web portal (sundhed.dk) that gives residents access to their own medical data from national health } \\
\text { databases, electronic health records, and medication registries. These data can also be accessed by the patient's GP and } \\
\text { hospital physicians. }\end{array}$ \\
\hline $\begin{array}{l}\text { Electronic medical } \\
\text { records }\end{array}$ & $\begin{array}{l}\text { Provides a complete integrated IT workplace for hospital clinicians that integrates patient records, administrative data, } \\
\text { medication use, bookings, and various test results (eg, laboratory, pathology, radiology, microbiology results). It } \\
\text { improves the efficiency of clinical processes and workflows, treatment continuity, and patient safety. There are two } \\
\text { types of systems: Systematic Columna Clinical Information System (MidtEPJ) used in the Central, North, and Southern } \\
\text { Regions and Epic's Healthcare Platform (Sundhedsplatformen) used in Region Zealand and the Capital Region. Records } \\
\text { are automatically and instantly shared across Regions with similar systems. }\end{array}$ \\
\hline $\begin{array}{l}\text { Shared medication } \\
\text { record }\end{array}$ & $\begin{array}{l}\text { Provides citizens and health care professionals, in both the primary and secondary health care sector, access to a } \\
\text { complete electronic record of each citizen's current prescription medications. This system simplifies communication } \\
\text { concerning medication among health care providers and reduces the risk of prescribing inappropriate medications. }\end{array}$ \\
\hline Telemedicine & $\begin{array}{l}\text { The } 2012 \text { National Telemedicine Action Plan operates five specific telemedicine initiatives, which form the basis for a } \\
\text { telemedicine program to pioneer future telemedicine initiatives. A national infrastructure for telemedicine has been } \\
\text { established as part of a planned large-scale implementation of telemedicine throughout the country. This infrastructure } \\
\text { includes standards and relevant reference architectures spanning the entire health care system, covering data mea- } \\
\text { surement, video, questionnaires, and images. }\end{array}$ \\
\hline
\end{tabular}




\section{Danish medical databases}

Denmark has a long tradition of routinely collecting data on many aspects of life and health in a multitude of registries and databases with population coverage. Examples of the types of data routinely generated during health care contacts are provided in Table 4. Each registry or database covers all residents in its geographical area (eg, Western Denmark ${ }^{17,18}$ or Denmark as a whole ${ }^{19}$ ) within a given time period. Total population registries, such as the Civil Registration System, contain data on all inhabitants in Denmark. ${ }^{20}$ Other registries cover all members of the Danish population with a given set of traits, exposures, or events, and hence are population-based registries..$^{20}$ Medical database is the term used for all types of registries and databases that contain health-related data. ${ }^{21}$ There are three types of medical databases in Denmark: administrative databases, health databases, and clinical quality databases (Figure 4). While a historic overview of all Danish medical databases can be found in Supplementary Table S1, we will in the following detail the spectrum of the available data.

\section{Administrative databases}

Most health care data used for research originate from administrative databases, which register individuals according to their residency in a specified geographic area, membership in a health insurance program, or attendance at a particular hospital or clinic - irrespective of the patients' diseases and the procedures used to treat them. ${ }^{21}$ Demographic, migration, and vital statistics data have been registered electronically on a daily basis since 1968 in the Danish Civil Registration System. ${ }^{16}$ Non-electronic population registrations date further back to $1924 .{ }^{16}$ Specific causes of death have been recorded in the Danish Registry of Causes of Deaths since $1943 .{ }^{22}$ Suicide and suicide attempts are recorded separately in the Danish Registry of Suicide (since 1970) ${ }^{22}$ and Registry for Suicide Attempts (since 1989). ${ }^{23}$ Hospital encounters (with admission type and dates, discharge diagnoses, and procedures) have been registered in the Danish National Patient Registry since 1977. ${ }^{19}$ Laboratory results are tracked by the Danish Clinical Laboratory Information System, with coverage of selected Regions since 1990 and nationwide since 2015. ${ }^{24}$ The Danish National Health Service Registry contains data from health contractors in the primary health sector, including information about patients, providers, and referral to health services. ${ }^{25}$ These data enable epidemiologists to control for health care-seeking behavior in their research. ${ }^{26}$ However, while this Registry includes such information as vaccination, it has minimal clinical information. ${ }^{25}$ Since 1957, conscription registries have collected data on height, weight, cognitive ability (as measured by the Børge Prien's test), and chronic diseases that could preclude military service (eg, asthma, epilepsy, or spinal osteochondrosis). ${ }^{14}$ This database, thereby, enables studies of life-long outcomes associated with BMI and cognition in young adulthood. ${ }^{27-30}$

The Danish National Prescription Registry contains detailed individual-level data on prescriber, patient, and products for all outpatient prescriptions dispensed since 1995. ${ }^{31}$ Aggregate data on sales of drugs and number of users in the primary sector are freely available online. ${ }^{32}$ Due to the opportunity for partial cost reimbursement to patients and frequent prescription together with other drugs, a sizeable proportion of over-the-counter drugs, such as low-dose aspirin and ibuprofen, are obtained by prescription and, therefore, also generate records in the Danish National Prescription Registry. ${ }^{33}$ Treatments dispensed during hospital stays do not generate records in this Registry, however. Such treatments include all cancer medicines, which are dispensed nearly exclusively at hospitals to free patients from copayments. Use of some cancer treatments, especially if they are expensive, may be recorded in the Danish National Patient Registry. ${ }^{19}$

Labor market and socioeconomic data are used increasingly in epidemiological research, either as exposures, for control of confounding, or as study endpoints. Denmark has numerous individual databases on education, ${ }^{34}$ income, ${ }^{35}$ employment, ${ }^{36}$ and housing ${ }^{37}$ (Table S1). Most information essential for research has been combined in the Integrated Database for Labour Market Research, ${ }^{38}$ which includes detailed data on individuals (eg, family, marital status, education, work experience, unemployment, and income), employment type (eg, position title, full-time/part-time, hourly pay, seniority, and changes in employment), and workplaces and companies (eg, date of establishment, industry, and location). Another data source, the DREAM database, ${ }^{39}$ allows weekly follow-up of individuals receiving any public transfer payment, and, therefore, allows for follow-up of social and economic consequences of diseases. An example is return to the workforce after cardiac arrest. ${ }^{40}$

\section{Health databases}

Health databases collect health data for the purpose of surveillance and research. The spectrum of health 
Table 4 Health care contacts and main sources of routinely collected health data in Denmark

\begin{tabular}{|c|c|c|c|}
\hline $\begin{array}{l}\text { Type of data } \\
\text { source }\end{array}$ & $\begin{array}{l}\text { Examples of key } \\
\text { databases }\end{array}$ & Health care contacts & Selected variables* \\
\hline \multirow[t]{6}{*}{$\begin{array}{l}\text { Administrative } \\
\text { databases }\end{array}$} & $\begin{array}{l}\text { Danish Civil Registration } \\
\text { System }^{16}\end{array}$ & $\begin{array}{l}\text { - Birth } \\
\text { - Death } \\
\text { - Migration } \\
\text { - Partner status }\end{array}$ & $\begin{array}{l}\text { - Date of birth } \\
\text { - Sex } \\
\text { - Date of emigration and (re-)immigration } \\
\text { - Vital status with daily updates }\end{array}$ \\
\hline & $\begin{array}{l}\text { Danish Registry of Causes } \\
\text { of Death }\end{array}$ & - Death & $\begin{array}{l}\text { - Date of death } \\
\text { - Immediate cause of death } \\
\text { - Underlying cause of death } \\
\text { - Contributory causes of death }\end{array}$ \\
\hline & $\begin{array}{l}\text { Danish National Patient } \\
\text { Registry }^{19}\end{array}$ & $\begin{array}{l}\text { - Inpatient, outpatient, emergency hospital } \\
\text { encounter (one record per encounter) }\end{array}$ & $\begin{array}{l}\text { - Primary and secondary discharge diagnoses } \\
\text { - Date of contact } \\
\text { - Diagnostic tests (without results) } \\
\text { - Surgical procedures with dates } \\
\text { - Certain hospital-administered treatments } \\
\text { - Radiological examinations }\end{array}$ \\
\hline & $\begin{array}{l}\text { Danish National } \\
\text { Psychiatric Central } \\
\text { Research Registry }^{83}\end{array}$ & $\begin{array}{l}\text { - Inpatient, outpatient, emergency psy- } \\
\text { chiatric hospital encounters (one } \\
\text { record per encounter) }\end{array}$ & $\begin{array}{l}\text { - Date of contact } \\
\text { - Discharge diagnoses } \\
\text { - Treating department and hospital }\end{array}$ \\
\hline & $\begin{array}{l}\text { Danish National } \\
\text { Prescription Registry }{ }^{31} \dagger\end{array}$ & $\begin{array}{l}\text { - Outpatient dispensings of prescribed } \\
\text { drugs (one record per dispensing/drug) }\end{array}$ & $\begin{array}{l}\text { - Date of sale } \\
\text { - Prescriber type and specialty } \\
\text { - ATC code } \\
\text { - Brand and product number } \\
\text { - Formulation strength } \\
\text { - Amount dispensed (in DDDs) } \\
\text { - Route of administration } \\
\text { - Retail price and reimbursement amount }\end{array}$ \\
\hline & $\begin{array}{l}\text { Laboratory Information } \\
\text { Systems Database }{ }^{24}\end{array}$ & $\begin{array}{l}\text { - Laboratory tests performed in hospital- } \\
\text { based laboratories (one record per test) }\end{array}$ & $\begin{array}{l}\text { - Date of test } \\
\text { - Type of test } \\
\text { - Biological material tested } \\
\text { - Test result including units }\end{array}$ \\
\hline \multirow[t]{3}{*}{$\begin{array}{l}\text { Health } \\
\text { databases }\end{array}$} & Danish Cancer Registry ${ }^{41}$ & $\begin{array}{l}\text { - Incident primary malignancies (one } \\
\text { record per primary malignancy) }\end{array}$ & $\begin{array}{l}\text { - Date of diagnosis } \\
\text { - Cancer site } \\
\text { - Stage at diagnosis } \\
\text { - Morphology/histology }\end{array}$ \\
\hline & $\begin{array}{l}\text { Danish Medical Birth } \\
\text { Registry }^{84}\end{array}$ & $\begin{array}{l}\text { - Birth (live or still) (one record per } \\
\text { newborn) }\end{array}$ & $\begin{array}{l}\text { - CPR numbers of child, mother, and father } \\
\text { - Date of birth/delivery } \\
\text { - Sex, birth weight, gestational age, and } \\
\text { head circumference } \\
\text { - Multiplicity of gestation } \\
\text { - Apgar score } \\
\text { - Mode of delivery } \\
\text { - Congenital malformations in stillborn } \\
\text { - Maternal pre-pregnant body mass index } \\
\text { - Maternal smoking during pregnancy }\end{array}$ \\
\hline & $\begin{array}{l}\text { Danish National } \\
\text { Pathology Registry }\end{array}$ & $\begin{array}{l}\text { - Pathology examinations (one record per } \\
\text { test) }\end{array}$ & $\begin{array}{l}\text { - Date of examination } \\
\text { - Tissue type } \\
\text { - Type of test } \\
\text { - Result } \\
\text { - Location of tissue samples }\end{array}$ \\
\hline $\begin{array}{l}\text { Clinical quality } \\
\text { databases }^{59,60}\end{array}$ & $\begin{array}{l}\sim 100 \text { databases of dis- } \\
\text { eases or procedures }\end{array}$ & - Health care quality indicators & - Database-dependent variables ${ }^{85}$ \\
\hline
\end{tabular}

Notes: *The unique 10-digit Central Personal Register (CPR) number is used to identify persons in all data sources.

†Similar variables registered in the Danish National Health Service Prescription Database. ${ }^{86}$

Abbreviations: ATC code, Anatomical Therapeutic Chemical code; DDD, defined daily dose. 
databases is wide and covers disease/procedure registries, researcher-initiated cohorts, and biobanks.

Disease registries capture patients at the time of disease detection (typically first-time diagnosis or initiation of disease-defining treatment). ${ }^{21}$ Procedure registries capture patients undergoing a particular procedure in a defined population. ${ }^{21}$ Examples of disease or procedure registries include the Danish Cancer Registry ${ }^{41}$ (incident primary malignancies) and the Western Denmark Heart Registry (cardiac interventions). ${ }^{17,18}$ Danish disease/procedure registries also cover genetic tests (eg, the Cytogenetic Registry ${ }^{42}$ ), fertility treatments (the Danish Fertility Database ${ }^{43}$ and the In Vitro Fertilisation Registry ${ }^{44}$ ), abortions (Registry of Legally Induced Abortions ${ }^{45}$ ), births (Medical Birth Registry ${ }^{46}$ ), and congenital diseases (eg, the Danish Cerebral Palsy Registry, ${ }^{47}$ the Danish Registry of Congenital Heart Disease, ${ }^{48}$ and the Danish Registry of Congenital Malformations ${ }^{49}$ ).

Researcher-initiated cohorts may include individuals according to prespecified criteria other than diseases and procedures, such as area of residency, age, sex, pregnancy planning, adoption, military conscription, prescription redemption in specified geographic area, or survey participation.
Thus, researcher-initiated cohorts may 1) be derived from existing administrative databases for the purpose of research (eg, the regional prescription databases) or other health databases (eg, the Danish Twin Registry ${ }^{50}$ ); 2) represent classic cohort studies with prospective enrollment and follow-up (eg, the Copenhagen City Heart Study, which has been following 23,891 women and men of 20 years or older since $1976 ;{ }^{51,52}$ the Diet, Cancer and Health Study, which has been following 57,053 cancer-free participants aged 50-64 years since $1993 ;^{53}$ and the Danish National Birth Cohort, which has followed 100,000 pregnant women and their offspring since 1996) ${ }^{54}$ and 3) include participants of population surveys (eg, the "How are you" survey, which commenced in $2006,{ }^{55}$ and the Danish Health Examination Survey, which commenced in 2007). ${ }^{56}$ Population surveys provide detailed data on, eg, lifestyle factors and behaviors, which are not recorded in most other data sources. Surveys, cross-sectional by design, become longitudinal when follow-up questionnaires/examinations are carried out. Even in the absence of pre-planned follow-up, Danish survey participants are effectively cohorts with lifelong follow-up (containing baseline survey data) by virtue of linkage to any other data source for additional baseline data and outcomes. ${ }^{16,19}$

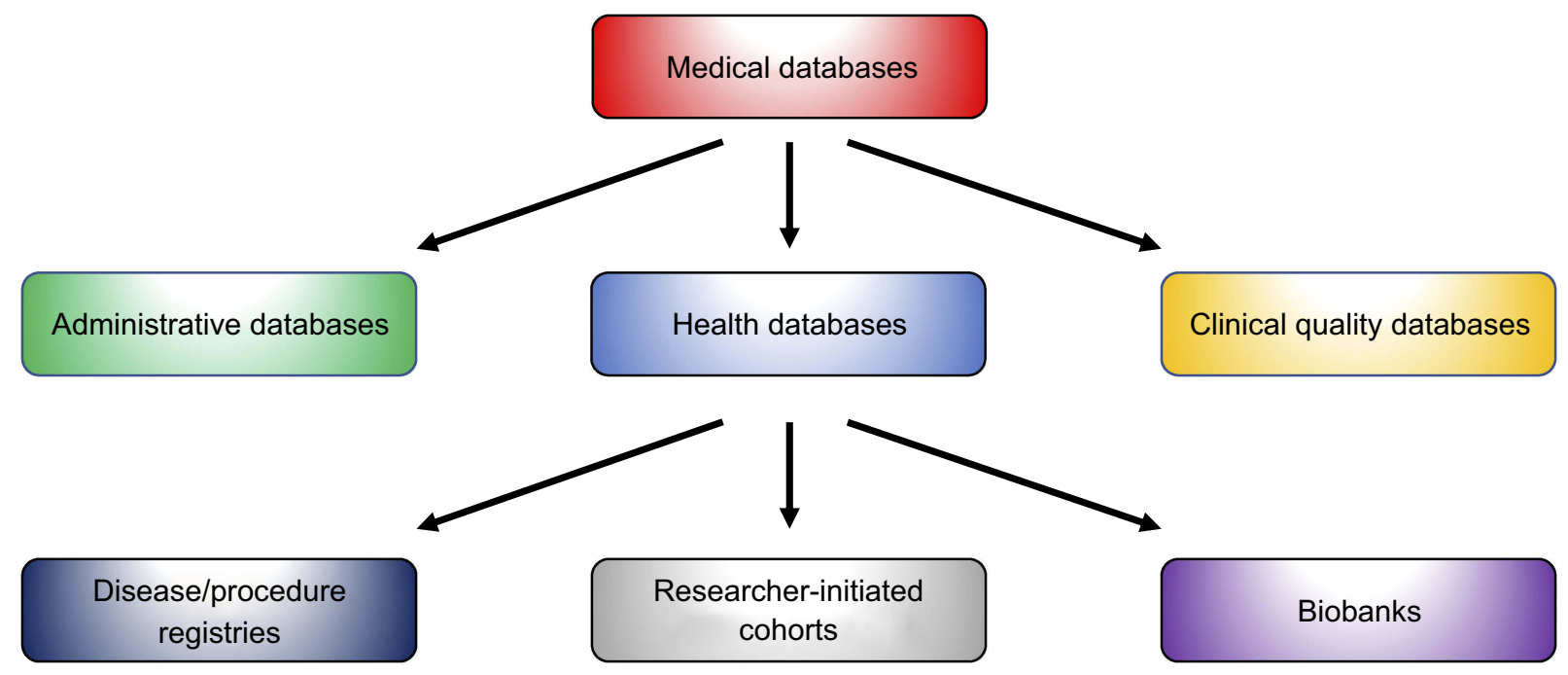

All types of registries and databases that contain health-related data

Register individuals according to geographic area, health insurance program, or attendance at a particular hospital or clinic

Register health data for the purpose of surveillance and research

Register detailed clinical data for clinical quality control

Register patients according to diagnosis or procedure

Register individuals according to prespecified criteria (eg, area of residency, age, sex, conscription, adoption, pregnancy, or survey participation)

Store biological samples (eg, blood and tissue)

Figure 4 Classification of medical databases. 
The renowned Danish biobanks play a key role in research seeking to advance precision medicine. The Danish National Biobank, established in 2012 at the State Serum Institute, has consolidated information on all biological specimens collected in the national health care system into a single registry - the Danish National Biobank Registry - permitting researchers to identify biological material available for each disease through an online search function (detailed in Table S1). ${ }^{57}$ In addition, the Danish Regions maintains the "Bio and Genome Bank Denmark", the parent registry for individual biobanks dedicated to blood donation, genetics, diabetes, rheumatology, cancer, and pathology. Importantly, the Danish National Pathology Registry contains nationwide records for all pathology specimens analyzed in Denmark since $1997 .^{58}$

\section{Clinical quality databases}

Clinical databases contain information regarding patients' medical histories, laboratory and radiology findings, and treatment. $^{21}$ The data are collected during the course of routine clinical care, but are also often used to assess the effectiveness of treatments and adverse effects and to address other research questions. ${ }^{21}$ A special group of clinical databases are the clinical quality databases, which collect detailed clinical data for clinical quality control. $^{21}$ The Danish clinical quality databases are regulated by the government and funded by the Regions. There are close to 100 of these databases, and more are being established. ${ }^{59}$ Data on quality indicators and standards for good clinical practice are compiled and analyzed by health care professionals. A report containing analyses and recommendations for each database is published on a yearly basis to ensure continued quality improvement. The Danish clinical quality databases have been described in detail in a recent review series. ${ }^{60} \mathrm{~A}$ Danish Clinical Quality Databases agency oversees the databases, with the main focus of facilitating continuous improvement of the databases and their utilization from clinical, administrative, and research points of view.

\section{Data not available}

While the Danish data sources are rich and in many ways unique in an international context, there remains room for improvement. Clinical data from general practice are not routinely collected in Denmark, in contrast to several other European countries, eg, in the UK (CPRD, THIN, and QResearch), ${ }^{61-63}$ Norway (KUHR), ${ }^{64}$ Sweden (eg, SPCCD), ${ }^{65}$ Finland (AvoHILMO), ${ }^{66}$ Netherlands (PHARMO), ${ }^{67}$ or Spain (SIDIAP and BIFAP). ${ }^{68}$ The
Danish National Patient Registry does not capture diagnoses made in general practice unless a patient has a hospital encounter with that disease. A database of diagnoses from general practice was established for a brief period in $2007,{ }^{69}$ but was closed due to uncertainty about its legal foundation. In some cases, it is possible to identify diseases not leading to a hospital encounter from other databases, most commonly, by a treatment proxy from prescription data (eg, herpes zoster, diabetes, depression, or hypertension $)^{26,70,71}$ or by means of laboratory results. ${ }^{24}$

In addition, lifestyle variables are generally missing from most databases containing routinely collected data. While data on lifestyle factors can be obtained from various population health surveys, these sources are not nationwide or continuously updated. As well, results of examinations and procedures are not available in the Danish National Patient Registry. ${ }^{19}$ Finally, services provided by some components of the Danish health care system, such as home nursing, home care service, and rehabilitation, are not registered systematically and, therefore, rarely used for research.

\section{Data quality Validity}

Data quality is typically measured by validity and completeness. Validity, in the context of health research, refers to the extent to which a variable measures the intended health condition or event. The positive predictive value (PPV) of a health record is the most frequently reported validity measure, defined as the proportion of patients registered with a disease who truly have the disease. Medical record review is a common reference standard used in validation studies to confirm the presence or absence of a disease. ${ }^{19}$ Other types of reference standards include patient self-reports, physicians' reports, autopsy reports, and alternative data sources with presumably higher data quality (such as clinical quality data, laboratory data, and pathology data). ${ }^{19}$

In general, data in health and clinical quality databases have high validity and completeness, because they are collected prospectively with the aim of quality control and clinical care. Consultants within each medical field register the data in clinical quality databases, further increasing the accuracy of the data. Although also registered prospectively, the validity of clinical data in the administrative databases may vary considerably among databases and within each database. On one hand, detailed data on education, ${ }^{34}$ income, ${ }^{35}$ social benefits, ${ }^{35}$ housing, ${ }^{37}$ 
blood tests, ${ }^{24}$ dispensed medications, ${ }^{31}$ ethnicity (country of birth of immigrants and descendants), ${ }^{72}$ and all-cause mortality ${ }^{16}$ are considered complete and valid. On the other hand, the validity of clinical data extracted from hospital records ${ }^{19}$ and death certificates ${ }^{22}$ depend on many factors, most importantly the individual variable registered, time period studied, and the level of specialization of the reporting department. ${ }^{19}$

Because the Danish National Patient Registry is among the most widely used administrative databases in epidemiological research, continuous efforts are made to validate its data. Three categories of validation studies have been performed:

1. Government-initiated systematic validation of personal demographic data, hospital admission data, and overall diagnoses within different clinical specialties. ${ }^{73-75}$ Such validation studies, performed by the Danish Health and Medicines Authority, have shown that data on admission/discharge dates, hospital/department codes, and CPR numbers are accurate, whereas the PPV of disease codes varies between specialties and depends on inclusion of primary or secondary diagnoses and whether validation was done at the three- or five-digit level of the International Classification of Diseases.

2. Investigator-driven systematic validation of individual diagnoses, examinations, procedures, and surgery codes within a specific clinical specialty. Only a few examples exist, within the fields of cardiology $^{76,77}$ and gynecology/obstetrics. ${ }^{78}$

3. Investigator-driven ad hoc validation of study-specific variables, the most common type of validation study. A bibliography of the validation studies is freely available. $^{19}$

To increase PPV, variables used for research may incorporate, in addition to diagnostic codes, data such as admission type (acute vs elective), patient contact type (inpatient vs outpatient), specialty department, diagnostic specification (primary vs secondary diagnoses), procedures, in-hospital medical treatment, or medication proxies (eg, antidiabetic and antihypertensive drugs). The PPVs of health events included in the Danish National Patient Registry range from below $15 \%$ to $100 \%$. This fact underscores the need to validate the specific variables used in a study, rather than drawing conclusions about their expected accuracy from findings for other variables included in a given registry. ${ }^{19}$

\section{Completeness}

Completeness refers to the proportion of true health events in the population correctly captured by a data source. ${ }^{21}$ Completeness of diseases can be measured in relation to all individuals in the general population or all patients admitted/ treated for a specific disease. Completeness is largely determined by the registry's sensitivity and depends on the amount of missing data. Ascertainment of completeness relative to the general population is often difficult. Because of its nationwide coverage, the Danish National Patient Registry is most often used to study disease occurrence. However, data completeness in this registry depends on hospitalization patterns and diagnostic accuracy. Thus, conditions such as myocardial infarction, stroke, or hip fracture, which should always lead to a hospital encounter, are consistently registered. In contrast, lifestyle risk factors (overweight, smoking, excessive alcohol consumption, and physical inactivity) and conditions treated primarily in primary care, such as osteoporosis, hypertension, or uncomplicated diabetes, are not.

Linkage to other routine registries can sometimes compensate for the Danish National Patient Registry's incomplete capture of certain conditions. For instance, diabetes can be identified from the presence of at least one redeemed outpatient prescription for insulin or an oral antidiabetic drug in the Danish National Prescription Registry $^{31}$ and/or by an inpatient or outpatient hospital diagnosis of type 1 or type 2 diabetes. ${ }^{79}$ Recent studies have supplemented the diabetes algorithm by using data on glycosylated hemoglobin $A_{1 c}$ measurements from the Laboratory Database, ${ }^{24}$ by increasing specificity through exclusion of patients treated with metformin for polycystic ovarian syndrome, ${ }^{80}$ and by differentiating type 1 and type 2 diabetes using information on age at diagnosis combined with the presence of insulin monotherapy. ${ }^{79}$

\section{Danish health statistics}

Danish population-based registries provide health statistics of immense value for researchers, as well as for politicians, administrators, the media, the pharmaceutical industry, and others. Aggregated data on drug use and selected disease trends are freely available online.${ }^{32}$ Key statistics characterizing the Danish population and the health care system are provided in Tables 5 and $6^{8,81}$

The Danish population grew from 5.1 million in 1980 to 5.8 million in 2018. This population growth is in the lower range compared with other European countries. Although 
Table 5 Danish population statistics, 2014

\begin{tabular}{|l|l|}
\hline Population growth & \\
Population size, $\mathrm{n}$ & $5,627,235$ \\
Live births, $\mathrm{n}$ & 56,870 \\
Deaths, $\mathrm{n}$ & 51,340 \\
Immigrants, $\mathrm{n}$ & 87,563 \\
Emigrants, $\mathrm{n}$ & 59,226 \\
\hline Longevity and mortality & \\
Persons aged 65 years or older, \% & 18 \\
Life expectancy at birth for men, years & 78.6 \\
Life expectancy at birth for women, years & 82.5 \\
Life expectancy at 65 years for men, years & 18.1 \\
Life expectancy at 65 years for women, years & 20.8 \\
Annual number of deaths per I,000 population & 9.1 \\
Infant deaths per I,000 population, $\mathrm{n}$ & 4 \\
\hline Fertility and childbirth & \\
Average number of births per woman & 1.7 \\
Mean maternal age at first delivery, years & 29.1 \\
\hline
\end{tabular}

Notes: Data from the Ministry of Health (http://www.sum.dk), ${ }^{5}$ Statistics Denmark (http://Statistikbanken.dk), ${ }^{81}$ and Organization for Economic Cooperation and Development (https://data.oecd.org). ${ }^{8}$

Table 6 Danish health care statistics, 2014

\begin{tabular}{|l|l|}
\hline Preventive care & \\
Children age $\sim$ I year receiving measles immunization, \% & 90 \\
Children age $\sim$ I year receiving diphtheria, tetanus, and & 94 \\
pertussis immunization, \% & \\
Influenza vaccination rates in the population $\geq 65$ years, \% & 43 \\
\hline Health care access & \\
Capacity in primary sector, number of residents per health & \\
professional & \\
General practitioners, $\mathrm{n}$ & 1,599 \\
Medical specialists, $\mathrm{n}$ & 6,237 \\
Dentists and dental hygienists, $\mathrm{n}$ & 2,408 \\
Physiotherapists, $\mathrm{n}$ & 4,223 \\
Chiropractors, $\mathrm{n}$ & 20,944 \\
Podiatrists, $\mathrm{n}$ & 5,990 \\
Psychologists, $\mathrm{n}$ & 6,643 \\
Capacity in public hospitals, residents per full-time & \\
employee & \\
Physicians, $\mathrm{n}$ & 365 \\
Nurses, $\mathrm{n}$ & 157 \\
Other health care professionals, $\mathrm{n}$ & 418 \\
Assistants, $\mathrm{n}$ & 550 \\
Others, $\mathrm{n}$ & 174 \\
Hospital beds per I,000 residents, $\mathrm{n}$ & 2.7 \\
Waiting time for elective hospital surgery, mean days & 49 \\
Doctors per I,000 residents, $\mathrm{n}$ & 3.7 \\
\hline
\end{tabular}

(Continued)
Table 6 (Continued)

\begin{tabular}{|c|c|}
\hline \multicolumn{2}{|l|}{ Health care utilization } \\
\hline Physician consultations per residents, $\mathrm{n}$ & 4.5 \\
\hline Primary sector & \\
\hline Patients per 1,000 residents, $\mathrm{n}$ & 893 \\
\hline Contacts per patient, mean & 11.3 \\
\hline General practice & \\
\hline Physical consultations during daytime per I,000 residents, $\mathrm{n}$ & 3,843 \\
\hline Telephone and e-mail consultations during daytime per & 2,893 \\
\hline $\mathrm{I}, 000$ residents, $\mathrm{n}$ & \\
\hline Consultations after daytime hours per 1,000 residents, $n$ & 482 \\
\hline Public hospitals & \\
\hline Patients per 1,000 residents, $n$ & 674 \\
\hline Hospitalizations per 1,000 residents, $n$ & 1,133 \\
\hline Outpatient contacts per 1,000 residents, $n$ & 12,606 \\
\hline Private hospitals, publicly funded care & \\
\hline Patients per 1,000 residents, $n$ & 9 \\
\hline Hospitalizations per 1,000 residents, $n$ & 10 \\
\hline Outpatient contacts per 1,000 residents, $n$ & 256 \\
\hline Private hospitals, privately funded care & \\
\hline Patients per 1,000 residents, $n$ & 10 \\
\hline Hospitalizations per 1,000 residents, $n$ & 11 \\
\hline Outpatient contacts per 1,000 residents, $n$ & 228 \\
\hline Non-psychiatric hospital, publicly financed & \\
\hline Patients with hospitalizations per 1,000 residents, $n$ & 121 \\
\hline Hospitalizations per 1,000 residents, $n$ & 204 \\
\hline Average length of stay, days & 3.5 \\
\hline Patients with outpatient contacts per 1,000 residents, $n$ & 466 \\
\hline Outpatient contacts per 1,000 residents, $n$ & 2,291 \\
\hline Psychiatric hospitals & \\
\hline Patients per 1,000 residents, $n$ & 25 \\
\hline Contacts per 1,000 residents, $\mathrm{n}$ & 219 \\
\hline Patients with hospitalizations per 1,000 residents, $n$ & 4.5 \\
\hline Hospitalizations per 1,000 residents, $n$ & 8.2 \\
\hline Average length of stay, days & 15 \\
\hline Patients with outpatient contacts per 1,000 residents, $n$ & 25 \\
\hline Outpatient contacts per 1,000 residents, $\mathrm{n}$ & 211 \\
\hline $\begin{array}{l}\text { Recipients of home care services (personal and/or practical } \\
\text { help), } \% \geq 65 \text { years }\end{array}$ & 12.2 \\
\hline
\end{tabular}

Notes: Data from the Ministry of Health (http://www.sum.dk), ${ }^{5}$ Statistics Denmark (Statistikbanken.dk), ${ }^{81}$ and Organization for Economic Cooperation and Development (https://data.oecd.org). ${ }^{8}$

births exceed deaths, the average number of births per woman is only 1.7. Among the Nordic countries, Denmark has the highest rate of in vitro fertilization treatments, amounting to nine treatments per 1,000 women aged 15-49 years compared with approximately five per 1,000 women in neighboring countries. $^{82}$

Longevity in Denmark has increased substantially over time, as shown in Figure 5. During 2014-2015, mean life 


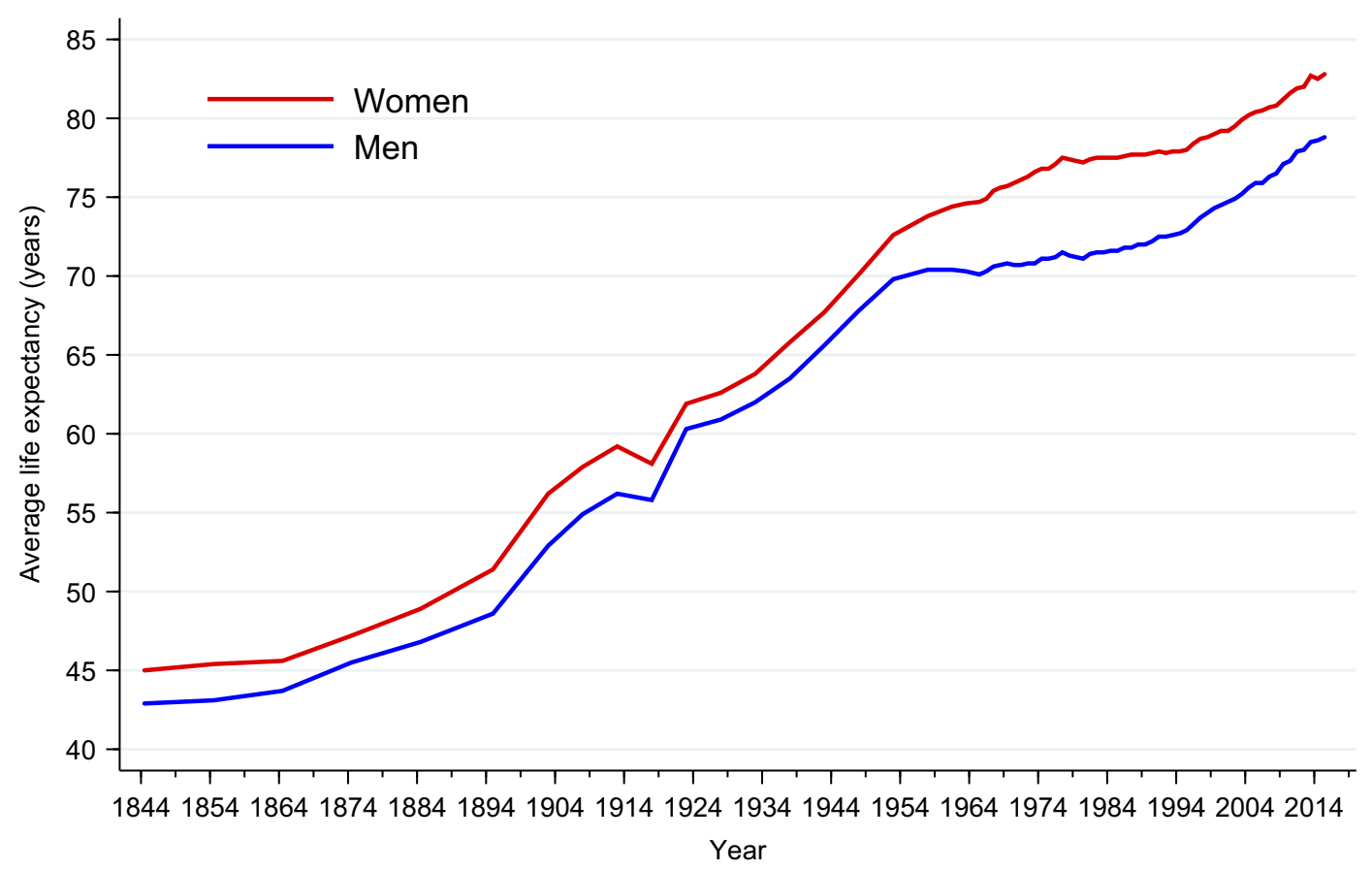

Figure 5 Sex-specific mean life expectancy at birth in Denmark, 1844-2014. StatBank Denmark. ${ }^{81}$

expectancy was 78.6 years for men and 82.5 years for women. Almost $20 \%$ of the Danish population is currently above 65 years of age. However, the increase in life expectancy has been smaller than that in most other Western European countries. Mortality in Denmark is among the highest in the Nordic countries. $^{82}$

The annual number of physician consultations per resident in Denmark was 4.5 in 2014, comparable to other Nordic countries. $^{8}$ Most persons $(90 \%)$ have at least one contact with the primary health care system each year. The total number of primary care contacts, including those with GPs, medical specialists, dentists, and physiotherapists, was 58.1 million in 2014, corresponding to 11.3 contacts per person on average. Annually, approximately $13 \%$ of the population is hospitalized, and the average length of hospital stay is 3.5 days in non-psychiatric departments and 15 days in psychiatric departments. Danish health care data, thus, provide many important indicators of the health care system and characteristics of the underlying population.

\section{Conclusions}

To interpret the results of studies based on Danish medical databases, it is necessary to understand the underlying health care system, its history, infrastructure, and quality of data registration - in short, how a given health contact becomes a data point. Denmark's constellation of universal health care, routine and long-standing registration of life and health events, and the ability to link administrative, health, and clinical quality databases at the individual level provide virtually unlimited possibilities for epidemiological research. Thus, the ability for researchers to reconstruct individual lives and health trajectories for members of an entire population without loss to follow-up enables future generations of patients to benefit from the experience of previous generations via evidence-based medical care.

\section{Data permission}

No data permission was needed.

\section{Ethics committee approval}

No ethics committee approval was needed.

\section{Transparency declaration}

The lead author affirms that the manuscript is an honest, accurate, and transparent account of the study being reported, that no important aspects of the study have been omitted, and that any discrepancies from the study as planned have been explained.

\section{Acknowledgments}

We thank the Danish National Archives, the Danish Clinical Registries (RKKP), and many senior researchers from the Universities of Aarhus, Copenhagen, and Odense, for review and comments on Table S1. The study was 
supported by the Department of Clinical Epidemiology's Research Foundation, by the Program for Clinical Research Infrastructure (PROCRIN) established by Lundbeckfonden and the Novo Nordisk Foundation, and by the Danish Research Council (grants 11-108354 and 11-115818). The funding sources had no role in the design, conduct, analysis, or reporting of the study.

\section{Author contributions}

HTS and MS conceived the study idea. All authors contributed to the study design. MS organized the writing and wrote the initial draft. All authors contributed toward drafting and critically revising the paper, gave final approval of the version to be published, and agree to be accountable for all aspects of the work.

\section{Disclosure}

VE reports institutional grants (none related to this work) from various pharmaceutical companies. The authors report no conflicts of interest in this work.

\section{References}

1. Frank L. Epidemiology. When an entire country is a cohort. Science. 2000;287(5462):2398-2399.

2. Pedersen KM, Christiansen T, Bech M. The Danish health care system: evolution - not revolution - in a decentralized system. Health Econ. 2005;14(S1):S41-S57. doi:10.1002/hec.1028

3. Christiansen T. Organization and financing of the Danish health care system. Health Policy. 2002;59(2):107-118.

4. Christiansen T. Ten years of structural reforms in Danish healthcare. Health Policy. 2012;106(2):114-119. doi:10.1016/j.healthpol.2012. 03.019

5. Ministry of Health. Healthcare in Denmark - an Overview. Version 1.2. ISBN: 978-87-7601-365-3. Copenhagen: Ministry of Health; 2017.

6. Danish Medicines Agency. Pharmacies in Denmark. Available from: https://laegemiddelstyrelsen.dk/en/pharmacies/pharmacies. Accessed February 1, 2019.

7. Sagan A, Thomson S, editors. Copenhagen (Denmark): European observatory on health systems and policies. Chapter 8. Denmark. In: Voluntary Health Insurance in Europe: Country Experience [Internet]. Observatory Studies Series, No. 42; 2016.

8. Organisation for Economic Co-operation and Development. OECD data. Available from: https://data.oecd.org. Accessed February 1, 2019.

9. AMGRoS. Pharmaceutical Procurement Service for the Five Regional Authorities in Denmark. Available from: www.amgros.dk/ en. Accessed February 1, 2019.

10. Møller Pedersen K. Pricing and reimbursement of drugs in Denmark. Eur J Health Econ. 2003;4(1):60-65. doi:10.1007/s10198-003-0165-6

11. Danish Medicines Agency. The Central Reimbursement Register. Available from: https://sundhedsstyrelsen.dk/en/medicines/reimburse ment/central-reimbursement-register. Accessed February 1, 2019.

12. Pedersen KM, Andersen JS, Søndergaard J. General practice and primary health care in Denmark. J Am Board Fam Med. 2012;25 (Suppl 1):S34-S38. doi:10.3122/jabfm.2012.02.110216
13. Danish Health Authority. Guideline on primary healthcare prevention for children and adolescents (in Danish: vejledning om forebyggende sundhedsydelser til børn og unge). Available from: www.sst.dk/ / media/6770049FEA8442DA8409E5127ABCAD24.ashx. Accessed on February 1, 2019.

14. Christensen GT, Skogstad S, Nissen LR, Osler M. Data resource profile: Danish Conscription Registry Data (DCRD). Int $J$ Epidemiol. 2018;47(4):1023-1024e. doi:10.1093/ije/dyx190

15. Danish Ministry of Health, the Danish Ministry of Finance, Danish Regions, and Local Government Denmark. Danish strategy for digital health 2018-2022. Available from: www.healthcaredenmark.dk/ news/new-danish-strategy-for-digital-health-2018-2022.aspx. Accessed February 1, 2019.

16. Schmidt M, Pedersen L, Sørensen HT. The Danish civil registration system as a tool in epidemiology. Eur J Epidemiol. 2014;29(8):541549. doi:10.1007/s10654-014-9930-3

17. Schmidt M, Maeng M, Madsen M, Sørensen HT, Jensen LO, Jakobsen C-J. The Western Denmark heart registry: its influence on cardiovascular patient care. J Am Coll Cardiol. 2018;71(11):12591272. doi:10.1016/j.jacc.2017.10.110

18. Nielsen LH, Nørgaard BL, Tilsted HH, et al. The Western Denmark cardiac computed tomography registry: a review and validation study. Clin Epidemiol. 2015;7:53-64. doi:10.2147/CLEP.S73728

19. Schmidt M, Schmidt SAJ, Sandegaard JL, Ehrenstein V, Pedersen L, Sørensen H. The Danish National patient registry: a review of content, data quality, and research potential. Clin Epidemiol. 2015;7:449-490. doi:10.2147/CLEP.S91125

20. Olsen J, Basso O, Sørensen HT. What is a population-based registry? Scand J Public Health. 1999;27(1):78.

21. Sørensen HT, Baron JA. Chapter 26. Medical databases. In: Olsen J, Greene N, Saracci R, Trichopoulos D, editors. Teaching epidemiology: a guide for teachers in epidemiology, public health and clinical medicine. Oxford, UK: United States of America, Oxford University Press; 2015:475-488.

22. Helweg-Larsen K. The Danish register of causes of death. Scand J Public Health. 2011;39(7 Suppl):26-29. doi:10.1177/1403494811399958

23. Christiansen E, Jensen BF. Register for suicide attempts. Dan Med Bull. 2004;51(4):415-417.

24. Grann AF, Erichsen R, Nielsen AG, Frøslev T, Thomsen RW. Existing data sources for clinical epidemiology: the clinical laboratory information system (LABKA) research database at Aarhus University, Denmark. Clin Epidemiol. 2011;3:133-138. doi:10.2147/ CLEP.S17901

25. Andersen JS, Olivarius NDF, Krasnik A. The Danish National Health service register. Scand J Public Health. 2011;39(7 Suppl):34-37. doi: $10.1177 / 1403494810394718$

26. Schmidt M, Sørensen HT, Pedersen L. Diclofenac use and cardiovascular risks: series of nationwide cohort studies. BMJ. 2018;k3426-10. doi:10.1136/bmj.k3426

27. Schmidt M, Bøtker HE, Pedersen L, Sørensen HT. Adult height and risk of ischemic heart disease, atrial fibrillation, stroke, venous thromboembolism, and premature death: a population based 36-year follow-up study. Eur J Epidemiol. 2014;29(2):111-118. doi:10.1007/ s10654-013-9867-y

28. Schmidt M, Bøtker HE, Pedersen L, Sørensen HT. Comparison of the frequency of atrial fibrillation in young obese versus young nonobese men undergoing examination for fitness for military service. Am J Cardiol. 2014;113(5):822-826. doi:10.1016/j.amjca rd.2013.11.037

29. Schmidt M, Johannesdottir SA, Lemeshow S, et al. Obesity in young men, and individual and combined risks of type 2 diabetes, cardiovascular morbidity and death before 55 years of age: a Danish 33year follow-up study. BMJ Open. 2013;3(4):e002698. doi:10.1136/ bmjopen-2013-002698 
30. Schmidt M, Johannesdottir SA, Lemeshow S, et al. Cognitive test scores in young men and subsequent risk of type 2 diabetes, cardiovascular morbidity, and death. Epidemiology. 2013;24(5):632-636. doi:10.1097/EDE.0b013e31829e0ea2

31. Pottegård A, Schmidt SAJ, Wallach-Kildemoes H, Sørensen HT, Hallas J, Schmidt M. Data resource profile: the Danish national prescription registry. Int J Epidemiol. 2017;46(3):798-798f. doi:10.1093/ije/dyw317

32. Schmidt M, Hallas J, Laursen M, Friis S. Data resource profile: Danish online drug use statistics (MEDSTAT). Int $J$ Epidemiol. 2016;45(5):1401-1402g. doi:10.1093/ije/dyw116

33. Schmidt M, Hallas J, Friis S. Potential of prescription registries to capture individual-level use of aspirin and other non-steroidal antiinflammatory drugs in Denmark: trends in utilization 1999-2012. Clin Epidemiol. 2014;6:155-168. doi:10.2147/CLEP.S59156

34. Jensen VM, Rasmussen AW. Danish education registers. Scand J Public Health. 2011;39(7 Suppl):91-94. doi:10.1177/1403494810394715

35. Baadsgaard M, Quitzau J. Danish registers on personal income and transfer payments. Scand J Public Health. 2011;39(7 Suppl):103105. doi:10.1177/1403494811405098

36. The National Centre for Register-based Research. The employment classification module. Available from: http://econ.au.dk/the-nationalcentre-for-register-based-research/danish-registers/the-employmentclassification-module-akm/. Accessed February 1, 2019.

37. Christensen G. The building and housing register. Scand J Public Health. 2011;39(7 Suppl):106-108. doi:10.1177/1403494811399168

38. Petersson F, Baadsgaard M, Thygesen LC. Danish registers on personal labour market affiliation. Scand J Public Health. 2011;39 (7_suppl):95-98. doi:10.1177/1403494811408483

39. Hjollund NH, Larsen FB, Andersen JH. Register-based follow-up of social benefits and other transfer payments: accuracy and degree of completeness in a Danish interdepartmental administrative database compared with a population-based survey. Scand J Public Health. 2007;35(5):497-502. doi:10.1080/14034940701271882

40. Kragholm K, Wissenberg M, Mortensen RN, et al. Return to work in out-of-hospital cardiac arrest survivors: a nationwide register-based follow-up study. Circulation. 2015;131(19):1682-1690. doi:10.1161/ CIRCULATIONAHA.114.011366

41. Gjerstorff ML. The Danish Cancer Registry. Scand J Public Health. 2011;39(7 Suppl):42-45. doi:10.1177/1403494810393562

42. Thygesen LC, Daasnes C, Thaulow I, Bronnum-Hansen H. Introduction to Danish (nationwide) registers on health and social issues: structure, access, legislation, and archiving. Scand J Public Health. 2011;39(7 Suppl):12-16. doi:10.1177/1403494811399956

43. Knudsen LB. The Danish fertility database. Dan Med Bull. 1998;45 (2):221-225

44. Andersen AN, Westergaard HB, Olsen J. The Danish in vitro fertilisation (IVF) register. Dan Med Bull. 1999;46(4):357-360.

45. Blenstrup LT, Knudsen LB. Danish registers on aspects of reproduction. Scand J Public Health. 2011;39(7 Suppl):79-82. doi:10.1177 1403494811399957

46. Bliddal M, Broe A, Pottegård A, Olsen J, Langhoff-Roos J. The Danish medical birth register. Eur J Epidemiol. 2018;33(1):27-36. doi:10.1007/s10654-018-0356-1

47. Uldall P, Michelsen SI, Topp M, Madsen M. The Danish cerebral palsy registry. A registry on a specific impairment. Dan Med Bull. 2001;48(3):161-163.

48. Olsen M, Videbæk J, Johnsen SP. The Danish register of congenital heart disease. Scand J Public Health. 2011;39(7 Suppl):50-53. doi:10.1177/1403494811399169

49. Larsen H, Nielsen GL, Bendsen J, Flint C, Olsen J, Sørensen HT. Predictive value and completeness of the registration of congenital abnormalities in three Danish population-based registries. Scand $J$ Public Health. 2003;31(1):12-16.

50. Skytthe A, Ohm Kyvik K, Vilstrup Holm N, Christensen K. The Danish twin registry. Scand J Public Health. 2011;39(7_suppl):7578. doi:10.1177/1403494810387966
51. Schnohr P, Jensen G, Lange P, Scharling H. The Copenhagen city heart study. Eur Heart J Suppl. 2001;3(suppl H):H1-H83. doi:10.1016/S1520-765X(01)90110-5

52. Aguib Y, Suwaidi AJ. The Copenhagen city heart study (Østerbroundersøgelsen). Global Cardiol Sci Pract. 2015;2015 (3):33. doi: $10.5339 /$ gcsp. 2015.33

53. Tjønneland A, Olsen A, Boll K, et al. Study design, exposure variables, and socioeconomic determinants of participation in diet, cancer and health: a population-based prospective cohort study of 57,053 men and women in Denmark. Scand J Public Health. 2007;35 (4):432-441. doi:10.1080/14034940601047986

54. Olsen J, Melbye M, Olsen SF. The Danish national birth cohort - its background, structure and aim. Scand J Public Health. 2001;29 (4):300-307.

55. Center for Public Health and Quality Improvement, Central Denmark Region. How are you? Available from: www.defactum.dk/omDEFACTUM/projektsite/hvordan-har-du-det/. Accessed February 1, 2019.

56. Eriksen L, Grønbaek M, Helge JW, Tolstrup JS, Curtis T. The Danish health examination survey 2007-2008 (DANHES 2007-2008). Scand J Public Health. 2011;39(2):203-211. doi:10.1177/1403494810393557

57. State Serum Institute. The Danish national biobank. Available from: www.danishnationalbiobank.com. Accessed February 1, 2019.

58. Erichsen R, Lash TL, Hamilton-Dutoit SJ, Bjerregaard B, Vyberg M, Pedersen L. Existing data sources for clinical epidemiology: the Danish national pathology registry and data bank. Clin Epidemiol. 2010;2:51-56.

59. Danish Clinical Registries (in Danish, Regionernes Kliniske Kvalitetsudviklingsprogram, RKKP). Danish clinical quality databases. Available from: www.rkkp.dk/in-english/. Accessed February $1,2019$.

60. Sørensen HT, Pedersen L, Jorgensen J, Ehrenstein V. Danish clinical quality databases - an important and untapped resource for clinical research. Clin Epidemiol. 2016;8:425-742. doi:10.2147/CLEP.S113265

61. Lewis JD, Schinnar R, Bilker WB, Wang X, Strom BL. Validation studies of the health improvement network (THIN) database for pharmacoepidemiology research. Pharmacoepidemiol Drug Saf. 2007;16(4):393-401. doi:10.1002/pds.1335

62. Herrett E, Gallagher AM, Bhaskaran K, et al. Data resource profile: clinical Practice Research Datalink (CPRD). Int J Epidemiol. 2015;44 (3):827-836. doi:10.1093/ije/dyv098

63. Hippisley-Cox J, Stables D, Pringle M. QRESEARCH: a new general practice database for research. J Innov Health Inform. 2014;12(1):4950. doi:10.14236/jhi.v12i1.108

64. Norwegian Health Authority (Helsedirektoratet). Health Checks and Payments (KUHR) database. Available from: https://helsedirektora tet.no/kuhr-databasen. Accessed February 1, 2019.

65. Hasselström J, Zarrinkoub R, Holmquist C, et al. The Swedish Primary Care Cardiovascular Database (SPCCD): 74751 hypertensive primary care patients. Blood Press. 2013;23(2):116-125. doi:10.3109/08037051.2013.814829

66. Finnish National Institute for Health and Welfare. Register of primary health care visits. Available from: https://thl.fi/en/web/thlfi-en/statis tics/information-on-statistics/register-descriptions/register-of-pri mary-health-care-visits\#data. Accessed February 1, 2019.

67. PHARMO. General practitioner database. Available from: https:// www.pharmo.nl/what-we-have/pharmo-database-network/generalpractitioner-database/. Accessed February 1, 2019.

68. SIDIAP. The information system for research in primary care in Spain. Available from: www.sidiap.org/index.php/en. Accessed February 1, 2019.

69. Schroll H, Paulsen MS, Skjoldaa L, Thomsen JL. [Danish general practice database]. Ugeskr Laeger. 2012;174(42):2541.

70. Sundbøll J, Schmidt M, Adelborg K, et al. Impact of pre-admission depression on mortality following myocardial infarction. $\mathrm{Br} J$ Psychiatry. 2017;210(5):356-361. doi:10.1192/bjp.bp.116.194605 
71. Schmidt SAJ, Vestergaard M, Baggesen LM, Pedersen L, Schønheyder HC, Sørensen HT. Prevaccination epidemiology of herpes zoster in Denmark: quantification of occurrence and risk factors. Vaccine. 2017;35(42):5589-5596. doi:10.1016/j.vaccine.2017.08.065

72. Norredam M, Kastrup M, Helweg-Larsen K. Register-based studies on migration, ethnicity, and health. Scand J Public Health. 2011;39(7 Suppl):201-205. doi:10.1177/1403494810396561

73. Danish Health and Medicines Authority. [Evaluation of the Danish national patient registry 1990]. Hosp Stat II. 1993;57:1-69.

74. Jürgensen HJ, Frølund C, Gustafsen J, Mosbech H, Guldhammer B, Mosbech J. Registration of diagnoses in the Danish national registry of patients. Methods Inf Med. 1986;25(3):158-164.

75. Division of Health Planning at C.F. Møller on behalf of The Danish National Board of Health. Projekt vedrørende datakvalitet i Landspatientregistret [Project concerning data quality in The Danish national patient registry]. Copenhagen: C.F. Møller - Healthcare Service; 2004. Danish.

76. Sundbøll J, Adelborg K, Munch T, et al. Positive predictive value of cardiovascular diagnoses in the Danish national patient registry: a validation study. BMJ Open. 2016;6(11):e012832. doi:10.1136/bmjopen-2016-012832

77. Adelborg K, Sundbøll J, Munch T, et al. Positive predictive value of cardiac examination, procedure and surgery codes in the Danish national patient registry: a population-based validation study. $B M J$ Open. 2016;6(12):e012817. doi:10.1136/bmjopen-2016-012817

78. Langhoff-Roos J, Rasmussen S. Validering af Landspatientregistret (LPR) mhp. Obstetrisk Forskning og Kvalitetssikring [Danish health and medicines authority. Copenhagen: Sundhedsstyrelsen; 2003. Danish.
79. Thomsen RW, Hundborg HH, Lervang -H-H, Johnsen SP, Sørensen HT, Schønheyder HC. Diabetes and outcome of community-acquired pneumococcal bacteremia: a 10-year population-based cohort study. Diabetes Care. 2004;27(1):70-76.

80. Christiansen C, Johansen M, Christensen S, O`Brien JM, Tønnesen E, Sørensen H. Preadmission metformin use and mortality among intensive care patients with diabetes: a cohort study. Crit Care. 2013;17(5):R192. doi:10.1186/cc12734

81. Statistics Denmark. StatBank Denmark. Available from: Statistikbanken.dk. Accessed February 1, 2019.

82. NOMESCO's Health Statistics for the Nordic Countries 2017. Available from: http://nowbase.org/da/publications. Accessed February 1, 2019.

83. Mors O, Perto GP, Mortensen PB. The Danish psychiatric central research register. Scand J Public Health. 2011;39(7 Suppl):54-57. doi:10.1177/1403494810395825

84. Knudsen L, Olsen J. The Danish medical birth registry. Dan Med Bull. 1998;45(3):320-323.

85. Clinical Epidemiology. Thematic series on the Danish clinical quality databases - an important and untapped resource for clinical research. Available from: https://www.dovepress.com/clini cal-epidemiology-archive43-collection3. Accessed February 1, 2019.

86. Johannesdottir SA, Horvath-Puho E, Ehrenstein V, Schmidt M, Pedersen L, Sørensen HT. Existing data sources for clinical epidemiology: the Danish national database of reimbursed prescriptions. Clin Epidemiol. 2012;4:303-313. doi:10.2147/CLEP. S37587 


\section{Supplementary materials}

Table SI Danish administrative, health, and clinical quality databases

\begin{tabular}{|c|c|c|c|c|}
\hline \multirow[t]{2}{*}{ Decade } & \multirow[t]{2}{*}{ Type of registry } & \multicolumn{3}{|c|}{ Coverage period (year) } \\
\hline & & From & Nationwide & To \\
\hline & Administrative databases & & & \\
\hline 1930s & Danish Road Traffic Accidents Registry' & 1930 & 1930 & Ongoing \\
\hline $1840 s$ & Registry of Causes of Death ${ }^{2}$ & $1943^{*}$ & 1943 & Ongoing \\
\hline \multirow[t]{2}{*}{$1960 \mathrm{~s}$} & Danish Civil Registration System ${ }^{3}$ & $1968^{*}$ & 1968 & Ongoing \\
\hline & Danish Psychiatric Central Research Registry ${ }^{4}$ & $1969 *$ & 1969 & Ongoing \\
\hline \multirow[t]{13}{*}{ I970s } & Danish Registry of Suicide ${ }^{1,2}$ & 1970 & 1970 & 1998 \\
\hline & Danish Mortality and Occupation Database ${ }^{\prime}$ & 1970 & 1970 & Ongoing \\
\hline & Danish Income Statistics Registry ${ }^{5}$ & 1970 & 1970 & Ongoing \\
\hline & Danish Registry of Pension Statistics' & 1970 & 1970 & Ongoing \\
\hline & Danish Population Statistics Registry' & 1971 & |97| & Ongoing \\
\hline & Danish Population Education Registry ${ }^{6,7}$ & 1973 & 1973 & Ongoing \\
\hline & Danish Registry for Work-related Accidents and Diseases ${ }^{8}$ & 1973 & 1973 & Ongoing \\
\hline & Danish Student Registry ${ }^{6}$ & 1974 & 1974 & Ongoing \\
\hline & Danish Employment Classification Module (AKM) ${ }^{9}$ & 1976 & 1976 & Ongoing \\
\hline & Danish Central Registry of Buildings and Dwellings (BBR) ${ }^{10}$ & 1976 & 1976 & Ongoing \\
\hline & Danish National Patient Registry (DNPR) ${ }^{\prime \prime}$ & 1977 & 1978 & Ongoing \\
\hline & Danish Academic Achievement Registry ${ }^{6}$ & 1977 & 1978 & Ongoing \\
\hline & Danish Unemployment Statistics Registry' & 1979 & 1979 & Ongoing \\
\hline \multirow[t]{8}{*}{$1980 \mathrm{~s}$} & Integrated Database for Labour Market Research (IDA) ${ }^{9}$ & 1980 & 1980 & Ongoing \\
\hline & Danish Registry-based Labour Force Statistics (RAS) ${ }^{9}$ & 1981 & 1981 & Ongoing \\
\hline & Danish Authorisation Registry' & 1982 & 1982 & Ongoing \\
\hline & Danish Sickness Benefits Statistics Registry' & 1983 & 1983 & Ongoing \\
\hline & Danish Labour Force Survey ${ }^{9}$ & 1984 & 1984 & Ongoing \\
\hline & Danish Coherent Social Statistics' & 1984 & 1984 & Ongoing \\
\hline & Danish Social Research Registry' & 1989 & 1989 & Ongoing \\
\hline & Danish Registry for Suicide Attempts ${ }^{12}$ & 1989 & 1989 & Ongoing \\
\hline \multirow[t]{16}{*}{ I990s } & Danish Hospital Utilisation Registry' & 1990 & 1990 & Ongoing \\
\hline & Danish National Health Insurance Service Registry ${ }^{13}$ & 1990 & 1990 & Ongoing \\
\hline & Establishment-related Employment (ERE) Statistics ${ }^{9}$ & 1990 & 1990 & Ongoing \\
\hline & Danish Database for Public Transfer Payments (DREAM) ${ }^{14}$ & 1991 & 1991 & Ongoing \\
\hline & Danish Patient Compensation Association Database ${ }^{15}$ & 1992 & 1992 & Ongoing \\
\hline & Danish Registry of Preventive Measures' & 1994 & 1994 & Ongoing \\
\hline & Danish Registry for Labour Market Policy Measures (AMFORA)' & 1994 & 1994 & Ongoing \\
\hline & Danish National Prescription Registry ${ }^{16}$ & 1995 & 1995 & Ongoing \\
\hline & Danish Registry of Drug Abusers Receiving Treatment ${ }^{\prime}$ & 1996 & 1996 & Ongoing \\
\hline & Danish Online Drug Use Statistics (MEDSTAT) ${ }^{17}$ & 1996 & 1996 & Ongoing \\
\hline & Danish Social Pensions Registry' & 1996 & 1996 & Ongoing \\
\hline & Danish Adult Education and Continuing Training Registry ${ }^{6}$ & 1997 & 1997 & Ongoing \\
\hline & Danish Children's Database' & 1997 & 1997 & Ongoing \\
\hline & Danish Registry of Municipal Health Services' & 1997 & 1997 & Ongoing \\
\hline & Danish Clinical Laboratory Information System ${ }^{18}$ & 1997 & 2015 & Ongoing \\
\hline & Danish Registry of Coercive Measures in Psychiatric Treatment' & 1999 & 1999 & Ongoing \\
\hline \multirow{4}{*}{ 1930s } & Health databases & & & \\
\hline & Disease/procedure registries & & & \\
\hline & Danish von Hippel-Lindau (vHL) Registry ${ }^{19}$ & 1930 & 1930 & 2010 \\
\hline & Danish Tuberculosis Registry ${ }^{20}$ & 1936 & 1936 & 1987 \\
\hline
\end{tabular}

(Continued) 
Table SI (Continued)

\begin{tabular}{|c|c|c|c|c|}
\hline \multirow[t]{2}{*}{ Decade } & \multirow[t]{2}{*}{ Type of registry } & \multicolumn{3}{|c|}{ Coverage period (year) } \\
\hline & & From & Nationwide & To \\
\hline \multirow[t]{3}{*}{ 1940s } & Danish Huntington's Disease Registry (DHR) ${ }^{19,21}$ & 1940 & 1940 & Ongoing \\
\hline & Danish Cancer Registry (DCR) ${ }^{22}$ & 1943 & 1943 & Ongoing \\
\hline & Danish Multiple Sclerosis Registry ${ }^{23}$ & 1948 & 1948 & Ongoing \\
\hline \multirow[t]{2}{*}{ 1950s } & Danish National Cerebral Palsy Registry ${ }^{24}$ & 1950 & 1995 & 2007 \\
\hline & Danish Registry for Escherichia and Klebsiella Surveillance ${ }^{25}$ & 1959 & 1959 & Ongoing \\
\hline \multirow[t]{3}{*}{$1960 \mathrm{~s}$} & Danish Cytogenetic Registry ${ }^{19}$ & 1960 & 1960 & Ongoing \\
\hline & Danish Registry of Congenital Heart Disease ${ }^{26}$ & 1963 & 1963 & Ongoing \\
\hline & Danish Porphyria Registry ${ }^{19}$ & $\sim 1969$ & $\sim 1969$ & Ongoing \\
\hline \multirow[t]{4}{*}{ 1970s } & Danish Polyposis Registry ${ }^{27}$ & 197| & $197 \mid$ & Ongoing \\
\hline & Danish Central Odontological Registry (SCOR) ${ }^{28}$ & 1972 & 1972 & Ongoing \\
\hline & Danish Registry of Legally Induced Abortions ${ }^{29}$ & 1973 & 1973 & 1994 \\
\hline & Danish Medical Birth Registry ${ }^{30}$ & $1973^{*}$ & 1973 & Ongoing \\
\hline \multirow[t]{4}{*}{ 1980s } & Danish Fertility Database ${ }^{29}$ & 1980 & 1980 & Ongoing \\
\hline & Danish Cholecystolithiasis Survey ${ }^{3 !}$ & 1982 & - & Ongoing \\
\hline & Danish Registry of Congenital Malformations ${ }^{32}$ & 1983 & 1983 & 1995 \\
\hline & Danish Family Archive for Genetic Eye Diseases ${ }^{19}$ & 1985 & 1985 & Ongoing \\
\hline \multirow[t]{8}{*}{ 1990s } & Danish National Registry on Regular Dialysis and Transplantation (NRDT) ${ }^{33}$ & 1990 & 1990 & Ongoing \\
\hline & Danish Retinitis Pigmentosa Registry ${ }^{19}$ & 1990 & 1990 & Ongoing \\
\hline & Danish Hereditary Nonpolyposis Colorectal Cancer (HNPCC) Registry ${ }^{19}$ & 1991 & 1995 & Ongoing \\
\hline & Danish In Vitro Fertilisation Registry ${ }^{29}$ & 1994 & 1994 & Ongoing \\
\hline & Danish Obstetric Registry ${ }^{34}$ & 1996 & - & Ongoing \\
\hline & Danish HIV Cohort Study ${ }^{35}$ & 1998 & 1998 & Ongoing \\
\hline & Hereditary Breast and Ovarian Cancer (HBOC) Registry ${ }^{19}$ & 1999 & 1999 & Ongoing \\
\hline & Western Denmark Heart Registry ${ }^{36,37}$ & 1999 & - & Ongoing \\
\hline \multirow[t]{5}{*}{2000 s } & Danish Collaborative Bacteraemia Network (DACOBAN) database ${ }^{38}$ & 2000 & - & 2011 \\
\hline & Danish Cystic Fibrosis Patient Registry ${ }^{19}$ & 2001 & 2001 & Ongoing \\
\hline & Danish Cancer in Primary Care (CaP) cohort $^{39}$ & 2004 & - & 2010 \\
\hline & Danish Heart Statistics ${ }^{40}$ & 2006 & 2006 & Ongoing \\
\hline & Danish National Diabetes Registry ${ }^{41}$ & 2006 & 2006 & Ongoing \\
\hline \multirow[t]{4}{*}{$2010 \mathrm{~s}$} & Danish National Type 2 Diabetes (DD2) Cohort ${ }^{42}$ & 2010 & 2010 & Ongoing \\
\hline & Danish Hereditary Angioedema Registry ${ }^{19}$ & 2011 & 2011 & Ongoing \\
\hline & Danish Clinical Registry of People with Chronic Back Pain (SpineData) ${ }^{43}$ & 2011 & - & Ongoing \\
\hline & Researcher-initiated cohorts & & & \\
\hline 1870s & Danish Twin Registry ${ }^{44}$ & 1870 & 1870 & Ongoing \\
\hline I920s & Danish Adoption Registry ${ }^{45,46}$ & 1924 & 1924 & 1947 \\
\hline 1930s & Copenhagen School Health Records Registry ${ }^{47}$ & 1936 & - & 2005 \\
\hline \multirow[t]{4}{*}{ 1950s } & Danish Multi-Generation Registry (MGR) $)^{3,48}$ & 1953 & 1953 & Ongoing \\
\hline & Danish Conscription Registry Data (DCRD) ${ }^{49}$ & $1957^{\dagger}$ & $1957^{\dagger}$ & $2015^{\dagger}$ \\
\hline & Copenhagen Perinatal Cohort ${ }^{50}$ & 1959 & - & 1961 \\
\hline & Copenhagen Infant Health Visitor Records (IHVR) $)^{51}$ & 1959 & - & 1967 \\
\hline \multirow[t]{3}{*}{$1960 \mathrm{~s}$} & Glostrup Population Studies ${ }^{52}$ & 1964 & - & Ongoing \\
\hline & Danish Longitudinal Survey of Youth ${ }^{53}$ & 1968 & $1968^{\ddagger}$ & Ongoing \\
\hline & Health Information System for the Central Denmark Region ${ }^{54}$ & 1968 & - & Ongoing \\
\hline 1970s & Copenhagen City Heart Study (Osterbro Study) ${ }^{55,56}$ & 1976 & - & $2003^{\S}$ \\
\hline \multirow[t]{3}{*}{ I980s } & Health Habits for Two $(\mathrm{HHf} 2)^{57}$ & 1984 & - & 1987 \\
\hline & Aarhus University Prescription Database ${ }^{58}$ & 1989 & - & 2016 \\
\hline & Aarhus Birth Cohort $(A B C)^{59}$ & 1989 & - & Ongoing \\
\hline
\end{tabular}

(Continued) 
Table SI (Continued)

\begin{tabular}{|c|c|c|c|c|}
\hline \multirow[t]{2}{*}{ Decade } & \multirow[t]{2}{*}{ Type of registry } & \multicolumn{3}{|c|}{ Coverage period (year) } \\
\hline & & From & Nationwide & To \\
\hline \multirow[t]{7}{*}{ 1990s } & Odense Pharmacoepidemiological Database (OPED) ${ }^{60}$ & 1990 & - & Ongoing \\
\hline & Copenhagen Puberty Study ${ }^{61}$ & 1991 & - & 2008 \\
\hline & Diet, Cancer, and Health Study ${ }^{62}$ & 1993 & - & Ongoing \\
\hline & Danish Longitudinal Survey of Children (DALSC) ${ }^{63}$ & 1996 & $1996^{\ddagger}$ & Ongoing \\
\hline & Danish National Birth Cohort (DNBC or Better health in generations) ${ }^{64}$ & 1996 & $1999^{\ddagger}$ & Ongoing \\
\hline & Copenhagen Male Reproductive Health Study ${ }^{65}$ & 1996 & - & 2010 \\
\hline & Danish Longitudinal Study on Ageing ${ }^{66}$ & 1997 & $1997^{\ddagger}$ & Ongoing \\
\hline \multirow[t]{9}{*}{ 2000s } & Copenhagen Prospective Studies on Asthma in Childhood (COPSAC) ${ }^{67}$ & 1998 & - & Ongoing \\
\hline & Copenhagen County Child Cohort $(\mathrm{CCCC} 2000)^{68}$ & 2000 & - & 2000 \\
\hline & Copenhagen Primary Care Differential Count (CopDiff) database ${ }^{69}$ & 2000 & - & 2010 \\
\hline & "How are you" survey ${ }^{70}$ & 2001 & $2010^{\ddagger}$ & Ongoing \\
\hline & General Practice Patient List Database $^{71}$ & 2002 & 2002 & Ongoing \\
\hline & Copenhagen General Population Study (CGPS) (Herlev/Osterbro Study) ${ }^{72}$ & 2003 & - & Ongoing \\
\hline & Danish National Health Service Prescription Database ${ }^{73}$ & 2004 & 2004 & Ongoing \\
\hline & Danish Health Examination Survey (DANHES) ${ }^{74,75}$ & 2007 & $2010^{\ddagger}$ & Ongoing \\
\hline & Danish Web-based Pregnancy Planning Study (Soon-Pregnant) ${ }^{76}$ & 2007 & - & Ongoing \\
\hline \multirow[t]{8}{*}{$2010 s$} & Danish Blood Donor Study (DBDS) ${ }^{77}$ & 2010 & 2010 & Ongoing \\
\hline & Odense Child Cohort $(\mathrm{OCC})^{78}$ & 2010 & - & 2012 \\
\hline & Danish General Suburban Population Study (GESUS) ${ }^{72}$ & 2010 & - & Ongoing \\
\hline & Danish Functional Disorders (DanFunD) cohort ${ }^{79}$ & 2011 & - & 2015 \\
\hline & Copenhagen Baby Heart ${ }^{80}$ & 2016 & - & 2018 \\
\hline & Copenhagen Mini-puberty Cohort & 2016 & - & 2019 \\
\hline & Lolland-Falster Health Study (LOFUS) ${ }^{81}$ & 2016 & - & Ongoing \\
\hline & Biobanks & & & \\
\hline 1990s & Danish National Pathology Registry ${ }^{82}$ & 1968 & 1997 & Ongoing \\
\hline $2000 s$ & Danish Cancer Biobank ${ }^{83}$ & 2009 & 2009 & Ongoing \\
\hline \multirow[t]{5}{*}{$2010 s$} & Danish National Biobank Registry ${ }^{84 \|}$ & 2012 & 2012 & Ongoing \\
\hline & Danish Rheuma Biobank $k^{83}$ & 2014 & 2014 & Ongoing \\
\hline & Danish Blood Donor Biobank ${ }^{83}$ & 2017 & 2017 & Ongoing \\
\hline & Danish Genetic Biobank ${ }^{83}$ & $\sim 2019^{\pi}$ & $\sim 2019^{\pi}$ & Ongoing \\
\hline & Danish Diabetes Biobank ${ }^{83}$ & $\sim 2019 \pi$ & $\sim 2019^{\pi}$ & Ongoing \\
\hline \multirow{3}{*}{ 1960s } & Clinical quality databases & & & \\
\hline & Danish Head and Neck Cancer Database (DaHanCaData) ${ }^{85}$ & $\sim 1960$ & $197 \mid$ & Ongoing \\
\hline & Danish Nephrology Registry (DNSL) ${ }^{86}$ & 1964 & 1990 & Ongoing \\
\hline 1970s & Danish Breast Cancer Cooperative Group (DBCG) ${ }^{87}$ & 1977 & 1977 & Ongoing \\
\hline \multirow[t]{6}{*}{ I980s } & Danish Pacemaker and ICD Registry ${ }^{88}$ & 1982 & 1982 & Ongoing \\
\hline & Danish National Lymphoma Registry ${ }^{89_{* *}}$ & 1982 & 2000 & Ongoing \\
\hline & Danish Testicular Cancer Database (DaTeCaData) ${ }^{90}$ & 1984 & $1984^{t \dagger}$ & Ongoing \\
\hline & Danish Childhood Cancer Registry ${ }^{91}$ & 1985 & 1985 & Ongoing \\
\hline & Danish Melanoma Database ${ }^{92}$ & 1985 & 1985 & Ongoing \\
\hline & Danish Vascular Registry (Karbase) ${ }^{93}$ & 1989 & 1989 & Ongoing \\
\hline \multirow[t]{6}{*}{ 1990s } & Danish Colorectal Cancer Group Database (DCCG) ${ }^{94}$ & 1994 & 2001 & Ongoing \\
\hline & Danish Hip Arthroplasty Registry ${ }^{95}$ & 1995 & 1995 & Ongoing \\
\hline & Danish HIV Cohort Study (DANHIV) ${ }^{35}$ & 1995 & 1995 & Ongoing \\
\hline & Danish Multiple Sclerosis Treatment Registry ${ }^{96}$ & 1996 & 1996 & Ongoing \\
\hline & Danish Registry for Childhood and Adolescent Diabetes (DanDiabKids) ${ }^{97 \neq ⿰}$ & 1996 & 2015 & Ongoing \\
\hline & Danish Knee Arthroplasty Registry ${ }^{98 \S \S}$ & 1997 & 2006 & Ongoing \\
\hline
\end{tabular}

(Continued) 
Table SI (Continued)

\begin{tabular}{|c|c|c|c|c|}
\hline \multirow[t]{2}{*}{ Decade } & \multirow[t]{2}{*}{ Type of registry } & \multicolumn{3}{|c|}{ Coverage period (year) } \\
\hline & & From & Nationwide & To \\
\hline \multirow{44}{*}{$2000 s$} & Danish Transfusion Database (DTDB) ${ }^{99}$ & 1997 & 2007 & Ongoing \\
\hline & Danish Inguinal Hernia database 100 & 1998 & 1998 & Ongoing \\
\hline & Danish Heart Registry ${ }^{101}$ & 1998 & 2000 & Ongoing \\
\hline & Danish National Database for Geriatrics ${ }^{102}$ & 1998 & 2005 & Ongoing \\
\hline & Danish National Acute Leukemia Registry ${ }^{103^{* *}}$ & 2000 & 2000 & Ongoing \\
\hline & Danish Lung Cancer Registry (DLCR) ${ }^{104}$ & 2000 & 2000 & Ongoing \\
\hline & Danish Rheumatology Database (DANBIO) ${ }^{105}$ & 2000 & 2006 & Ongoing \\
\hline & Danish Database for Hepatitis B and $C^{106}$ & 2002 & 2002 & Ongoing \\
\hline & Danish National Database for Contact Allergy ${ }^{88}$ & 2002 & 2002 & Ongoing \\
\hline & Danish Multidisciplinary Hip Fracture Registry (DMHFR) ${ }^{88 \S \S}$ & 2003 & 2003 & Ongoing \\
\hline & Danish Stroke Registry ${ }^{107}$ & 2003 & 2003 & Ongoing \\
\hline & Danish Schizophrenia Registry ${ }^{108}$ & 2003 & 2003 & Ongoing \\
\hline & Danish Hysterectomy and Hysteroscopy Database (DHHD) ${ }^{109}$ & 2003 & 2003 & Ongoing \\
\hline & Danish Esophagus, Cardia and Stomach Neoplasm Database (DECV) $)^{110}$ & 2003 & 2003 & Ongoing \\
\hline & Danish Heart Failure Registry ${ }^{\prime \prime \prime}$ & 2003 & 2005 & Ongoing \\
\hline & Danish Registry of Diabetic Retinopathy (DiaBase) $)^{1 / 2 \neq \ddagger}$ & 2003 & 2010 & Ongoing \\
\hline & Danish Cerebral Palsy Follow-up Program ${ }^{13}$ & 2003 & 2017 & Ongoing \\
\hline & Danish Database for Emergency Surgery ${ }^{1 / 4}$ & 2004 & 2004 & Ongoing \\
\hline & Danish Anesthesia Database ${ }^{115}$ & 2004 & 2004 & Ongoing \\
\hline & Danish Head Trauma Database ${ }^{88}$ & 2004 & 2004 & Ongoing \\
\hline & Danish Shoulder Arthroplasty Registry ${ }^{1 / 6 \S \S}$ & 2004 & 2006 & Ongoing \\
\hline & Danish Adult Diabetes Registry ${ }^{17 \ddagger \ddagger}$ & 2004 & 2006 & Ongoing \\
\hline & Danish Knee Ligament Reconstruction Registry ${ }^{\prime / 8 \S \S}$ & 2005 & 2005 & Ongoing \\
\hline & Danish Gynecological Cancer Database (DGCD) ${ }^{1 / 9}$ & 2005 & 2005 & Ongoing \\
\hline & Danish National Multiple Myeloma Registry (DaMyDa) ${ }^{120^{* *}}$ & 2005 & 2005 & Ongoing \\
\hline & Danish Myelodysplastic Syndrome Database ${ }^{103^{* *}}$ & 2005 & 2005 & Ongoing \\
\hline & Danish Intensive Care Database (DID) ${ }^{121}$ & 2005 & 2005 & Ongoing \\
\hline & Danish Early Pregnancy and Abortion Database $(\mathrm{TiGrAb})^{88}$ & 2006 & 2006 & Ongoing \\
\hline & Danish Cholecystectomy Database (DCD) ${ }^{122}$ & 2006 & 2006 & Ongoing \\
\hline & Danish Urogynaecological Database (DugaBase) ${ }^{123}$ & 2006 & 2007 & Ongoing \\
\hline & Danish Quality Database for Mammography Screening ${ }^{124}$ & 2007 & 2007 & Ongoing \\
\hline & Danish Biological Treatment in Danish Dermatology (DermBIO) ${ }^{88}$ & 2007 & 2009 & Ongoing \\
\hline & Danish Stoma Database ${ }^{125}$ & 2007 & - & Ongoing \\
\hline & Nordic Database for Rare Disease (RareDis) ${ }^{19}$ & 2006 & 2007 & Ongoing \\
\hline & Danish Registry of Chronic Obstructive Pulmonary Disease (DRKOL) ${ }^{126}$ & 2008 & 2008 & Ongoing \\
\hline & Danish National Chronic Lymphocytic Leukemia Registry ${ }^{127 * *}$ & 2008 & 2008 & Ongoing \\
\hline & Danish Ablation Database (Ablation.dk) ${ }^{88}$ & 2008 & 2008 & Ongoing \\
\hline & Danish Nonmelanoma Skin Cancer Dermatology Database ${ }^{128}$ & 2008 & 2011 & Ongoing \\
\hline & Danish Depression Database (DDD) ${ }^{129}$ & 2008 & 2011 & Ongoing \\
\hline & Danish Fetal Medicine Database (FØTO) ${ }^{130}$ & 2008 & 2011 & Ongoing \\
\hline & Danish Quality Database for Cervical Cancer Screening ${ }^{|3|}$ & 2009 & 2009 & Ongoing \\
\hline & Danish Sarcoma Database ${ }^{132}$ & 2009 & 2009 & Ongoing \\
\hline & Danish National Database for Obstructive Sleep Apnea (NDOSA) $)^{133}$ & 2009 & 2009 & Ongoing \\
\hline & Danish Neuro-Oncology Database (DNOR) ${ }^{134}$ & 2009 & 2009 & Ongoing \\
\hline \multirow[t]{4}{*}{$2010 \mathrm{~s}$} & Danish National Quality Database for Births $s^{135}$ & 2010 & 2010 & Ongoing \\
\hline & Danish Prostate Cancer Database (DaProCaData) ${ }^{136}$ & 2010 & 2010 & Ongoing \\
\hline & Danish Bariatric Surgery Registry (DFR) ${ }^{88}$ & 2010 & 2010 & Ongoing \\
\hline & Danish Renal Cancer Group Database (DaRenCaData) $)^{137}$ & 2010 & 2010 & Ongoing \\
\hline
\end{tabular}

(Continued) 
Table SI (Continued)

\begin{tabular}{|c|c|c|c|c|}
\hline \multirow[t]{2}{*}{ Decade } & \multirow[t]{2}{*}{ Type of registry } & \multicolumn{3}{|c|}{ Coverage period (year) } \\
\hline & & From & Nationwide & To \\
\hline & Danish Organ Donation Database ${ }^{88}$ & 2010 & 2010 & Ongoing \\
\hline & Danish National Chronic Myeloid Neoplasia Registry ${ }^{138 * *}$ & 2010 & 2010 & Ongoing \\
\hline & Danish Palliative Care Database (DPD) ${ }^{139}$ & 2010 & 2010 & Ongoing \\
\hline & Danish National Quality Registration for Visual Impairment (Websyn) ${ }^{88}$ & 2010 & 2010 & Ongoing \\
\hline & Danish Penile Cancer Database $(\mathrm{DaPeCaData})^{140}$ & 2011 & 2011 & Ongoing \\
\hline & Danish Diabetes Database ${ }^{1 / 2}$ & 2011 & 2011 & Ongoing \\
\hline & Danish Ocular Oncology Database (DOOG) ${ }^{88}$ & 2011 & 2011 & Ongoing \\
\hline & Danish Pancreatic Cancer Database (DPCD) $)^{141}$ & 2011 & 2011 & Ongoing \\
\hline & Danish Fracture Database ${ }^{142}$ & $\sim 2011$ & 2015 & Ongoing \\
\hline & Danish Bladder Cancer Database (DaBlaCaData) $)^{143}$ & 2012 & 2012 & Ongoing \\
\hline & Danish Database for Acute and Emergency Hospital Contacts (DDAEHC) $)^{144}$ & 2013 & 2013 & Ongoing \\
\hline & Danish Liver and Bile Duct Cancer Database ${ }^{88}$ & 2013 & 2013 & Ongoing \\
\hline & Danish Back Pain Registry (COP-Spine) ${ }^{88}$ & 2013 & 2013 & Ongoing \\
\hline & Danish ADHD Database ${ }^{88}$ & 2013 & 2013 & Ongoing \\
\hline & Danish Cardiac Rehabilitation Database ${ }^{145}$ & 2013 & 2015 & Ongoing \\
\hline & Danish In-hospital Cardiac Arrest Registry (DANARREST) $)^{146}$ & 2013 & 2017 & Ongoing \\
\hline & Danish Colorectal Cancer Screening Database ${ }^{147}$ & 2014 & 2014 & Ongoing \\
\hline & Danish Prehospital Emergency Medical Service Registry ${ }^{148}$ & 2014 & 2014 & Ongoing \\
\hline & Danish Rapid Response System (RRS) Database ${ }^{149}$ & 2014 & - & Ongoing \\
\hline & Danish Registry for Biological Therapy in Inflammatory Bowel Disease (BiolBD) ${ }^{150}$ & 2015 & 2015 & Ongoing \\
\hline & Danish Trauma Registry ${ }^{88}$ & 2015 & 2015 & Ongoing \\
\hline & Danish Asthma Database ${ }^{151}$ & 2015 & 2015 & Ongoing \\
\hline & Danish Registry for Adolescents with Acquired Brain Injury (DRUE) ${ }^{88}$ & 2015 & 2015 & Ongoing \\
\hline & Danish National Quality Database for Spinal Cord Injury ${ }^{88}$ & 2015 & 2015 & Ongoing \\
\hline & Danish National Quality Database for Newborns ${ }^{88}$ & 2016 & 2016 & Ongoing \\
\hline & Danish Quality Database for Dementia (DanDem) ${ }^{88}$ & 2016 & 2016 & Ongoing \\
\hline & Danish Atrial Fibrillation Database $e^{88}$ & 2016 & 2016 & Ongoing \\
\hline & Danish Back Database ${ }^{88}$ & 2017 & 2017 & Ongoing \\
\hline & Danish Registry for Acute Coronary Syndrome (DanAKS) ${ }^{88}$ & 2019 & 2019 & Ongoing \\
\hline & Danish Forensic Psychiatric Quality Database ${ }^{88}$ & $\sim 2019 \pi$ & $\sim 2019 \pi$ & Ongoing \\
\hline & Danish Familial Hypercholesterolaemia Database ${ }^{88}$ & $\sim 2019^{\pi}$ & $\sim 2019^{\pi}$ & Ongoing \\
\hline
\end{tabular}

Notes: The authors have made every effort to maximize completeness of this list of medical databases; however, it is likely that some databases were inadvertently omitted. Should this be the case, the authors will be grateful for any suggestions for adding such databases to the list. *Electronic datasets are available in the coverage periods shown, but manual registered data supplement the Registry of Causes of Death on causes of death since 1875, ${ }^{2}$ the Danish Psychiatric Central Research Registry on psychiatric diagnoses since 1906 (nationwide since 1938), ${ }^{4}$ the Danish Civil Registration System on population registration since 1924, ${ }^{3}$ and the Danish Medical Birth Registry since $1968{ }^{29}{ }^{\dagger}$ The Danish Conscription Registry Data (birth year: 1929-1998/examination year: 1957-2015) consists of four subregistries with different birth year/examination periods: Danish Conscription Database (1929-60/1957-84), National Archives Database (1940-97/1987-201 I), Danish Defence Personnel Organisation Database (195088/1995-2005), and Danish Conscription Registry (1973-98/2006-15). ${ }^{49}{ }^{\ddagger}$ Nationally representative (and not necessarily nationwide) from this year onwards. ${ }^{\S}$ After 2003, the Copenhagen City Heart Study (Osterbro Study) ${ }^{51,52}$ continued as part of the larger Copenhagen General Population Study (Herlev/Osterbro Study). ${ }^{72}$ As of January 2019, the registry stores $>25.3$ million samples from 5.7 million people and includes the following biobanks: Danish National Biobank (including I million samples each year, phenylketonuria blood spot cards from all newborn Danes since 1982 (>2 million samples), and the State Serum Institute legacy collections (>4 million samples); the Danish National Birth Cohort (>600,000 samples from pregnant mothers and their children); the Copenhagen Hospital (Rigshospitalet) biobank (50,000 samples each year); the Diet, Cancer and Health Study (samples from >57,000 participants); Patobank (17 million samples from hospitals); Danish Cancer Biobank (blood and tissue samples from Danish cancer patients); Region Zealand biobank (samples from LOFUS); Danish Twin Registry (samples from $>86,000$ twin pairs); Odense Patient data Explorative Network's research samples from the Region of Southern Denmark); and samples from COPSAC, DD2, and DBDS. "Under establishment. **Subregistry of the Combined

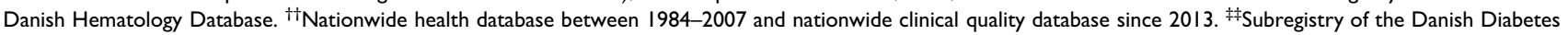
Database. ${ }^{\S}$ Subregistry of the Combined Danish Orthopaedic Database. 


\section{References}

1. The National Centre for Register-based Research. Danish registers. Availablefrom: http://econ.au.dk/the-national-centre-for-registerbased-research/danish-registers/. Accessed February 1, 2019.

2. Helweg-Larsen K. The Danish Register of causes of death. Scand $J$ Public Health. 2011;39(7 Suppl):26-29. doi:10.1177/140349481 1399958

3. Schmidt M, Pedersen L, Sørensen HT. The Danish civil registration system as a tool in epidemiology. Eur $J$ Epidemiol. 2014;29 (8):541-549. doi:10.1007/s10654-014-9930-3

4. Mors O, Perto GP, Mortensen PB. The Danish psychiatric central research register. Scand J Public Health. 2011;39(7 Suppl):54-57. doi:10.1177/1403494810395825

5. Baadsgaard M, Quitzau J. Danish registers on personal income and transfer payments. Scand J Public Health. 2011;39(7 Suppl):103105. doi: $10.1177 / 1403494811405098$

6. Jensen VM, Rasmussen AW. Danish education registers. Scand J Public Health. 2011;39(7 Suppl):91-94. doi:10.1177/1403494810394715

7. Pallesen PB, Tverborgvik T, Rasmussen HB, Lynge E. Data on education: from population statistics to epidemiological research. Scand J Public Health. 2010;38(2):177-183. doi:10.1177/ 1403494809357104

8. Danish Coordinating Body for Register-based Research. Danish registry for work-related accidents and diseases. Available from: www.registerforskning.dk/register-search-landing-page/?register_ id $=3568431$. Accessed February 1, 2019.

9. Petersson F, Baadsgaard M, Thygesen LC. Danish registers on personal labour market affiliation. Scand J Public Health. 2011;39(7_suppl):95-98. doi:10.1177/1403494811408483

10. Christensen G. The building and housing register. Scand J Public Health. 2011;39(7 Suppl):106-108. doi:10.1177/1403494811399168

11. Schmidt M, Schmidt SAJ, Sandegaard JL, Ehrenstein V, Pedersen L, Sørensen H. The Danish national patient registry: a review of content, data quality, and research potential. Clin Epidemiol. 2015;7:449-490. doi:10.2147/CLEP.S91125

12. Christiansen E, Jensen BF. Register for suicide attempts. Dan Med Bull. 2004;51(4):415-417.

13. Andersen JS, Olivarius NDF, Krasnik A. The Danish National health service register. Scand J Public Health. 2011;39(7 Suppl):34-37. doi:10.1177/1403494810394718

14. Hjollund NH, Larsen FB, Andersen JH. Register-based follow-up of social benefits and other transfer payments: accuracy and degree of completeness in a Danish interdepartmental administrative database compared with a population-based survey. Scand J Public Health. 2007;35(5):497-502. doi:10.1080/14034940701271882

15. Tilma J, Nørgaard M, Mikkelsen KL, Johnsen SP. Existing data sources for clinical epidemiology: the Danish patient compensation association database. Clin Epidemiol. 2015;7:347-353. doi:10.2147/CLEP.S84162

16. Pottegård A, Schmidt SAJ, Wallach-Kildemoes H, Sørensen HT, Hallas J, Schmidt M. Data resource profile: the Danish national prescription registry. Int J Epidemiol. 2017;46(3):798-798f. doi:10.1093/ije/dyw317

17. Schmidt M, Hallas J, Laursen M, Friis S. Data resource profile: Danish online drug use statistics (MEDSTAT). Int $J$ Epidemiol. 2016;45(5):1401-1402g. doi:10.1093/ije/dyw116

18. Grann AF, Erichsen R, Nielsen AG, Frøslev T, Thomsen RW. Existing data sources for clinical epidemiology: the clinical laboratory information system (LABKA) research database at Aarhus University, Denmark. Clin Epidemiol. 2011;3:133-138. doi:10.2147/CLEP.S17901

19. Nguyen-Nielsen M, Svensson E, Vogel I, Ehrenstein V, Sunde L. Existing data sources for clinical epidemiology: Danish registries for studies of medical genetic diseases. Clin Epidemiol. 2013;5 (1):249-262. doi:10.2147/CLEP.S45228
20. Danish Coordinating Body for Register-based Research. The Danish tuberculosis registry. Available from: www.registerforskn ing.dk/register-search-landing-page/?register_id $=3567082$. Accessed February 1, 2019.

21. Gilling M, Budtz-Jørgensen E, Boonen SE, et al. The Danish HD Registry-a nationwide family registry of HD families in Denmark. Clin Genet. 2017;92(3):338-341. doi:10.1111/cge.12984

22. Gjerstorff ML. The Danish cancer registry. Scand J Public Health. 2011;39(7 Suppl):42-45. doi:10.1177/1403494810393562

23. Koch-Henriksen N. The Danish multiple sclerosis registry: a 50year follow-up. Mult Scler. 1999;5(4):293-296. doi:10.1177/ 135245859900500418

24. Uldall P, Michelsen SI, Topp M, Madsen M. The Danish cerebral palsy registry. A registry on a specific impairment. Dan Med Bull. 2001;48(3):161-163.

25. Danish Coordinating Body for Register-based Research. Danish registry for escherichia and klebsiella surveillance. Available from: www.registerforskning.dk/register-search-landing-page/?reg ister_id=3591836. Accessed February 1, 2019.

26. Olsen M, Videbæk J, Johnsen SP. The Danish Register of congenital heart disease. Scand J Public Health. 2011;39(7 Suppl):50-53. doi: $10.1177 / 1403494811399169$

27. Bülow S. The Danish polyposis register - Description of the methods of detection and evaluation of completeness. Dis Colon Rectum. 1984;27(6):351-355.

28. Danish Coordinating Body for Register-based Research. Danish central odontological registry. Available from: www.registerforskn ing.dk/register-search-landing-page/?register_id $=3566624$. Accessed February 1, 2019.

29. Blenstrup LT, Knudsen LB. Danish registers on aspects of reproduction. Scand J Public Health. 2011;39(7 Suppl):79-82. doi:10.1177/1403494811399957

30. Bliddal M, Broe A, Pottegård A, Olsen J, Langhoff-Roos J. The Danish medical birth register. Eur J Epidemiol. 2018;33(1):27-36. doi:10.1007/s10654-018-0356-1

31. Jensen KH, Jørgensen T. Incidence of gallstones in a Danish population. Gastroenterology. 1991;100(3):790-794.

32. Larsen H, Nielsen GL, Bendsen J, Flint C, Olsen J, Sørensen HT. Predictive value and completeness of the registration of congenital abnormalities in three Danish population-based registries. Scand $J$ Public Health. 2003;31(1):12-16.

33. Hommel K, Rasmussen S, Madsen M, Kamper A-L. The Danish registry on regular dialysis and transplantation: completeness and validity of incident patient registration. Nephrol Dial Transplant. 2010;25(3):947-951. doi:10.1093/ndt/gfp571

34. Brixval CS, Thygesen L, Johansen N, et al. Validity of a hospitalbased obstetric register using medical records as reference. Clin Epidemiol;2015. 509. doi:10.2147/CLEP.S93675

35. Obel N, Engsig FN, Rasmussen LD, Larsen MV, Omland LH, Sørensen HT. Cohort profile: the Danish HIV cohort study. Int $J$ Epidemiol. 2009;38(5):1202-1206. doi:10.1093/ije/dyn192

36. Schmidt M, Maeng M, Madsen M, Sørensen HT, Jensen LO, Jakobsen C-J. The Western Denmark heart registry: its influence on cardiovascular patient care. J Am Coll Cardiol. 2018;71 (11):1259-1272.

37. Nielsen LH, Nørgaard BL, Tilsted HH, et al. The Western Denmark cardiac computed tomography registry: a review and validation study. Clin Epidemiol. 2015;7:53-64. doi:10.2147/ CLEP.S73728

38. Gradel K, Arpi M, Knudsen J, Schonheyder H, Ostergaard C, Søgaard M. The Danish Collaborative Bacteraemia Network (DACOBAN) database. Clin Epidemiol. 2014;6:301-308. doi:10.2147/CLEP.S66998

39. Jensen H, Larsen MB, Vedsted P, Torring ML. Existing data sources for clinical epidemiology: Danish cancer in primary care cohort. Clin Epidemiol. 2014;6:237-246. doi:10.2147/CLEP. S62855 
40. Schmidt M, Andersen LV, Friis S, Juel K, Gislason G. Data resource profile: Danish heart statistics. Int $J$ Epidemiol. 2017. doi:10.1093/ije/dyx108

41. Carstensen B, Kristensen JK, Marcussen MM, Borch-Johnsen K. The national diabetes register. Scand J Public Health. 2011;39(7 Suppl):58-61. doi:10.1177/1403494811404278

42. Christensen DH, Nicolaisen SK, Berencsi K, et al. Danish Centre for Strategic Research in Type 2 Diabetes (DD2) project cohort of newly diagnosed patients with type 2 diabetes: a cohort profile. BMJ Open. 2018;8(4):e017273. doi:10.1136/bmjopen-2017-017273

43. Kent P, Kongsted A, Jensen TS, Albert HB, Schiøttz-Christensen B, Manniche C. SpineData - a Danish clinical registry of people with chronic back pain. Clin Epidemiol. 2015;7:369-380. doi:10.2147/CLEP.S83830

44. Skytthe A, Ohm Kyvik K, Vilstrup Holm N, Christensen K. The Danish twin registry. Scand J Public Health. 2011;39(7_suppl):7578. doi:10.1177/1403494810387966

45. Petersen L, Sørensen TI. Studies based on the Danish Adoption Register: schizophrenia, BMI, smoking, and mortality in perspective. Scand J Public Health. 2011 Jul;39(7 Suppl):191-5.

46. Petersen L, Sørensen TIA. The Danish adoption register. Scand J Public Health. 2011;39(7 Suppl):83-86. doi:10.1177/140349481039 4714

47. Baker JL, Sørensen TIA. The Copenhagen school health records register. Scand J Public Health. 2011;39(7 Suppl):87-90. doi:10.1177/1403494810390727

48. Danish Coordinating Body for Register-based Research. The Danish multi-generation registry. Available from: www.register forskning.dk/projekter/mgr-lite/\#. Accessed February 1, 2019.

49. Christensen GT, Skogstad S, Nissen LR, Osler M. Data resource profile: Danish Conscription Registry Data (DCRD). Int $J$ Epidemiol. 2018;47(4):1023-1024e. doi:10.1093/ije/ dyx 190

50. Merrick J, Merrick Y, Zachau-Christiansen B. The Copenhagen Perinatal Cohort 1959-61. Int J Rehab Res. 1983;6(1):57-59. doi:10.1097/00004356-198303000-00008

51. Bjerregaard LG, Rasmussen KM, Michaelsen KF, et al. Effects of body size and change in body size from infancy through childhood on body mass index in adulthood. Int J Obes (Lond). 2014;38 (10):1305-1311. doi:10.1038/ijo.2014.108

52. Osler M, Linneberg A, Glümer C, Jørgensen T. The cohorts at the research centre for prevention and health, formerly 'The glostrup population studies'. Int $J$ Epidemiol. 2011;40(3):602-610. doi:10.1093/ije/dyq041

53. Danish National Centre for Social Research. Danish longitudinal survey of youth. Available from: https://dlsy.sfi.dk/dlsy-in-english/. Accessed February 1, 2019.

54. Schmidt SAJ, Vestergaard M, Baggesen LM, Pedersen L, Schønheyder HC, Sørensen HT. Prevaccination epidemiology of herpes zoster in Denmark: quantification of occurrence and risk factors. Vaccine. 2017;35(42):5589-5596. doi:10.1016/j. vaccine.2017.08.065

55. Schnohr P, Jensen G, Lange P, Scharling H. The Copenhagen city heart study. Eur Heart J Suppl. 2001;3(suppl H):H1-H83. doi:10.1016/S1520-765X(01)90110-5

56. Aguib Y, Suwaidi AJ. The Copenhagen city heart study (Østerbroundersøgelsen). Global Cardiol Sci Pract. 2015;2015 (3):33. doi:10.5339/gcsp.2015.33

57. Olsen J, Frische G, Poulsen AO, Kirchheiner H. Changing smoking, drinking, and eating behaviour among pregnant women in Denmark. Evaluation of a health campaign in a local region. Scand J Soc Med. 1989;17(4):277-280.

58. Ehrenstein V, Antonsen S, Pedersen L. Existing data sources for clinical epidemiology: Aarhus University prescription database. Clin Epidemiol. 2010;2:273-279. doi:10.2147/CLEP. S13458
59. Mortensen LM, Bech BH, Nohr EA, et al. Data resource profile: the Aarhus birth cohort biobank (ABC biobank). Int J Epidemiol. 2014;42(6):1697-1701. doi:10.1093/ije/dyt199

60. Hallas J, Hellfritzsch M, Rix M, Olesen M, Reilev M, Pottegård A. Odense pharmacoepidemiological database: a review of use and content. Basic Clin Pharmacol Toxicol. 2017;120(5):419-425. doi:10.1111/bcpt.12764

61. Aksglaede L, Sørensen K, Petersen JH, Skakkebæk NE, Juul A. Recent decline in age at breast development: the Copenhagen puberty study. Pediatrics. 2009;123(5):e932-e939. doi:10.1542/ peds.2008-2491

62. Tjønneland A, Olsen A, Boll K, et al. Study design, exposure variables, and socioeconomic determinants of participation in diet, cancer and health: a population-based prospective cohort study of 57,053 men and women in Denmark. Scand J Public Health. 2007;35(4):432-441. doi:10.1080/14034940601047986

63. Ottosen MH. Research on the Danish Longitudinal Survey of Children (DALSC) at the Danish National Centre for Social Research. Scand J Public Health. 2011;39(7 Suppl):121-125. doi:10.1177/1403494811399165

64. Olsen J, Melbye M, Olsen SF. The Danish national birth cohort its background, structure and aim. Scand J Public Health. 2001;29 (4):300-307.

65. Jørgensen N, Joensen UN, Jensen TK, et al. Human semen quality in the new millennium: a prospective cross-sectional populationbased study of 4867 men. BMJ Open. 2012;2(4):e000990-13. doi:10.1136/bmjopen-2012-000990

66. Danish National Centre for Social Research. Danish longitudinal study on aging. Available from: https://en.sfi.dk/projects/attri tion-in-the-danish-longitudinal-study-on-aging-11600/. Accessed February 1, 2019.

67. Bisgaard H. The Copenhagen prospective study on asthma in childhood (COPSAC): design, rationale, and baseline data from a longitudinal birth cohort study. Ann Allergy Asthma Immunol. 2004;93 (4):381-389. doi:10.1016/S1081-1206(10)61398-1

68. Skovgaard AM, Olsen EM, Houmann T, et al. The Copenhagen County child cohort: design of a longitudinal study of child mental health. Scand J Public Health. 2016;33(3):197-202. doi:10.1080/ 14034940510005662

69. Andersen CL, Siersma V, Karlslund W, et al. The Copenhagen primary care differential count (CopDiff) database. Clin Epidemiol. 2014;6:199-211. doi:10.2147/CLEP.S60991

70. Center for Public Health and Quality Improvement, Central Denmark Region. How Are You? Available from: www.defactum. dk/om-DEFACTUM/projektsite/hvordan-har-du-det/. Accessed February 1, 2019.

71. Kjaersgaard MIS, Vedsted P, Parner ET, et al. Algorithm linking patients and general practices in Denmark using the Danish national health service register. Clin Epidemiol. 2016;8:273-283. doi:10.2147/CLEP.S108307

72. Bergholdt HKM, Bathum L, Kvetny J, et al. Study design, participation and characteristics of the danish general suburban population study. Dan Med J. 2013;60(9):A4693.

73. Johannesdottir SA, Horvath-Puho E, Ehrenstein V, Schmidt M, Pedersen L, Sørensen HT. Existing data sources for clinical epidemiology: the danish national database of reimbursed prescriptions. Clin Epidemiol. 2012;4:303-313. doi:10.2147/CLEP. S37587

74. Eriksen L, Grønbaek M, Helge JW, Tolstrup JS, Curtis T. The Danish Health examination survey 2007-2008 (DANHES 20072008). Scand J Public Health. 2011;39(2):203-211. doi:10.1177/ 1403494810393557

75. Christensen AI, Ekholm O, Glümer C, et al. The Danish national health survey 2010. Study design and respondent characteristics. Scand J Public Health. 2012;40(4):391-397. doi:10.1177/ 1403494812451412 
76. Mikkelsen EM, Hatch EE, Wise LA, Rothman KJ, Riis A, Sørensen HT. Cohort profile: the Danish web-based pregnancy planning study-'snart-Gravid'. Int J Epidemiol. 2009;38(4):938943. doi:10.1093/ije/dyn191

77. Pedersen OB, Erikstrup C, Kotzé SR, et al. The Danish blood donor study: a large, prospective cohort and biobank for medical research. Vox Sang. 2012;102(3):271. doi:10.1111/j.14230410.2011.01553.x

78. Kyhl HB, Jensen TK, Barington T, et al. The odense child cohort: aims, design, and cohort profile. Paediatr Perinat Epidemiol. 2015;29(3):250-258. doi:10.1111/ppe.12183

79. Dantoft TM, Ebstrup JF, Linneberg A, et al. Cohort description: the Danish study of functional disorders. Clin Epidemiol. 2017;9:127139. doi:10.2147/CLEP.S129335

80. Sillesen A-S, Raja AA, Pihl C, et al. Copenhagen baby heart study: a population study of newborns with prenatal inclusion. Eur $J$ Epidemiol. 2019;34(1):79-90. doi:10.1007/s10654-018-0448-y

81. Jepsen R, Egholm CL, Brodersen J, et al. Lolland-Falster health study: study protocol for a household-based prospective cohort study. Scand J Public Health. 2018;12:1-9.

82. Erichsen R, Lash TL, Hamilton-Dutoit SJ, Bjerregaard B, Vyberg M, Pedersen L. Existing data sources for clinical epidemiology: the Danish National pathology registry and data bank. Clin Epidemiol. 2010;2:51-56.

83. Danish Regions. Bio and genome bank Denmark. Available from: www.regioner.dk/rbgben. Accessed February 1, 2019.

84. State Serum Institute. The Danish national biobank. Available from: www.danishnationalbiobank.com. Accessed February 1, 2019.

85. Overgaard J, Jovanovic A, Godballe C, Grau Eriksen J. The Danish head and neck cancer database. Clin Epidemiol. 2016;8:491-496. doi:10.2147/CLEP.S103591

86. Heaf J. The Danish nephrology registry. Clin Epidemiol. 2016;8:621-627. doi:10.2147/CLEP.S102649

87. Christiansen P, Ejlertsen B, Jensen M-B, Mouridsen H. Danish breast cancer cooperative group. Clin Epidemiol. 2016;8:445-449. doi:10.2147/CLEP.S99457

88. Danish Clinical Registries (in Danish, Regionernes Kliniske Kvalitetsudviklingsprogram, RKKP). Danish clinical quality databases. Available from: www.rkkp.dk/in-english/. Accessed February 1, 2019.

89. Arboe B, Josefsson P, Jørgensen J, et al. Danish national lymphoma registry. Clin Epidemiol. 2016;8:577-581. doi:10.2147/CLEP. S99470

90. Daugaard G, Kier M, Bandak M, et al. The Danish testicular cancer database. Clin Epidemiol. 2016;8:703-707. doi:10.2147/CLEP. S99493

91. Schroeder H, Rechnitzer C, Wehner P, et al. Danish childhood cancer registry. Clin Epidemiol. 2016;8:461-464. doi:10.2147/ CLEP.S99508

92. Rosenkrantz Hölmich L, Klausen S, Spaun E, et al. The Danish melanoma database. Clin Epidemiol. 2016;8:543-548. doi:10.2147/ CLEP.S99484

93. Eldrup N, Cerqueira CS, la Motte de L, Knudsen Rathenborg L, Hansen A. The Danish vascular registry, Karbase. Clin Epidemiol. 2016;8:713-718. doi:10.2147/CLEP.S99506

94. Ingeholm P, Gögenür I, Iversen L. Danish colorectal cancer group database. Clin Epidemiol. 2016;8:465-468. doi:10.2147/CLEP. S99481

95. Gundtoft P, Varnum C, Pedersen AB, Overgaard S. The Danish hip arthroplasty register. Clin Epidemiol. 2016;8:509-514. doi:10.2147/CLEP.S99498

96. Magyari M, Koch-Henriksen N, Sørensen P. The Danish multiple sclerosis treatment register. Clin Epidemiol. 2016;8:549-552. doi:10.2147/CLEP.S99500

97. Svensson J, Cerqueira CS, Kjærsgaard P, et al. Danish registry of childhood and adolescent diabetes. Clin Epidemiol. 2016;8:679683. doi:10.2147/CLEP.S99469
98. Pedersen AB, Mehnert F, Odgaard A, Schrøder HM. Existing data sources for clinical epidemiology: the Danish knee arthroplasty register. Clin Epidemiol. 2012;4:125-135. doi:10.2147/CLEP. S30050

99. Danish Transfusion Database. Homepage. Available from: www. dtdb.dk/forside/. Accessed February 1, 2019.

100. Friis-Andersen H, Bisgaard T. The Danish inguinal hernia database. Clin Epidemiol. 2016;8:521-524. doi:10.2147/CLEP. S99512

101. Özcan C, Juel K, Flensted Lassen J, Kappelgaard von L, Mortensen P, Gislason G. The Danish heart registry. Clin Epidemiol. 2016;8:503-508. doi:10.2147/CLEP.S99475

102. Kannegaard P, Vinding KL, Hare-Bruun H. National Database of geriatrics. Clin Epidemiol. 2016;8:731-735. doi:10.2147/CLEP. S99473

103. Ostgard L, Nørgaard JM, Raaschou-Jensen K, et al. The Danish national acute leukemia registry. Clin Epidemiol. 2016;8:553-560. doi:10.2147/CLEP.S99460

104. Jakobsen E, Rasmussen T. The Danish lung cancer registry. Clin Epidemiol. 2016;8:537-541. doi:10.2147/CLEP.S99458

105. Ibfelt EH, Jensen D, Hetland ML. The Danish nationwide clinical register for patients with rheumatoid arthritis: DANBIO. Clin Epidemiol. 2016;8:737-742. doi:10.2147/CLEP.S99490

106. Weis N, Thomsen R. [The Danish database for hepatitis B and C]. Ugeskr Laeger. 2012;174(42):2521.

107. Johnsen S, Ingeman A, Holmager Hunborg H, Zielke Schaarup S, Gyllenborg J. The Danish stroke registry. Clin Epidemiol. 2016;8:697-702. doi:10.2147/CLEP.S103662

108. Baandrup L, Cerqueira CS, Haller L, Korshoej L, Voldsgaard I, Nordentoft M. The Danish schizophrenia registry. Clin Epidemiol. 2016;8:691-695. doi:10.2147/CLEP.S99488

109. Topsoee M, Helene Ibfelt E, Settnes A. The Danish hysterectomy and hysteroscopy database. Clin Epidemiol. 2016;8(515-520). doi:10.2147/CLEP.S89480

110. Svendsen LB, Jensen LS, Nordsmark M. [Danish esophagus, cardia and stomach neoplasm database]. Ugeskr Laeger. 2012;174(42):2536.

111. Schjødt I, Nakano A, Egstrup K, Cerqueira CS. The Danish heart failure registry. Clin Epidemiol. 2016;8:497-502. doi:10.2147/ CLEP.S99504

112. Andersen N, Hjortdal J, Schielke K, et al. The Danish registry of diabetic retinopathy. Clin Epidemiol. 2016;8:613-619. doi:10.2147/ CLEP.S99507

113. Rasmussen H, Nordbye-Nielsen K, Møller-Madsen B, et al. The Danish cerebral palsy follow-up program. Clin Epidemiol. 2016;8:457-460. doi:10.2147/CLEP.S99474

114. Jørgensen H, Hylander Møller M, Rosenstock SJ, Thomsen RW. [The acute surgery database]. Ugeskr Laeger. 2012;174(42):2553.

115. Antonsen K, Rosenstock C, Hyldborg Lundstrom L. The Danish anaesthesia database. Clin Epidemiol. 2016;8:435-438. doi:10.2147/CLEP.S99517

116. Rasmussen JV, Jakobsen J, Brorson S, Olsen BS. The Danish shoulder arthroplasty registry: clinical outcome and short-term survival of 2,137 primary shoulder replacements. Acta Orthop. 2012;83(2):171-173. doi:10.3109/17453674.2012.665327

117. Jørgensen ME, Kolding J, Reventlov Husted G, Cerqueira CS, Rossing P. The Danish Adult Diabetes Registry. Clin Epidemiol. 2016;8:429-434. doi:10.2147/CLEP.S99518

118. Rahr-Wagner L, Lind M. The Danish knee ligament reconstruction registry. Clin Epidemiol. 2016;8:531-535. doi:10.2147/CLEP. S100670

119. Soerensen S, Bjørn S, Jochumsen K, et al. Danish gynecological cancer database. Clin Epidemiol. 2016;8:485-490. doi:10.2147/ CLEP.S99479

120. Gimsing P, Holmstrøm M, Wirenfelt Klausen T, et al. The Danish national multiple myeloma registry. Clin Epidemiol. 2016;8:583587. doi:10.2147/CLEP.S99463 
121. Christiansen CF, Møller MH, Nielsen H, Christensen S. The Danish intensive care database. Clin Epidemiol. 2016;8:525-530. doi:10.2147/CLEP.S99476

122. Harboe KM, Anthonsen K, Bardram L. Validation of data and indicators in the Danish cholecystectomy database. Int J Qual Health Care. 2009;21(3):160-168. doi:10.1093/intqhc/mzp009

123. Hansen UD, Gradel KO, Larsen MD. Danish urogynaecological database. Clin Epidemiol. 2016;8(709-712). doi:10.2147/CLEP.S89480

124. Mikkelsen E, Njor S, Vejborg I. Danish quality database for mammography screening. Clin Epidemiol. 2016;8:661-666. doi:10.2147/CLEP.S99467

125. Danielsen AK, Christensen BM, Mortensen J, Voergaard LL, Herlufsen P, Balleby L. Establishment of a regional Danish database for patients with a stoma. Colorectal Dis. 2014;17(1):O27O33. doi:10.1111/codi.12848

126. Lange P, Tøttenborg S, Sorknæs A, et al. Danish Register of chronic obstructive pulmonary disease. Clin Epidemiol. 2016;8:673-678. doi:10.2147/CLEP.S99489

127. Da Cunha-Bang C, Geisler C, Enggaard L, et al. The Danish national chronic lymphocytic leukemia registry. Clin Epidemiol. 2016;8:561-565. doi:10.2147/CLEP.S99486

128. Lamberg A, Sølvsten H, Lei U, et al. The Danish nonmelanoma skin cancer dermatology database. Clin Epidemiol. 2016;8:633636. doi:10.2147/CLEP.S99464

129. Videbech P, Deleuran A. The Danish depression database. Clin Epidemiol. 2016;8:475-478. doi:10.2147/CLEP.S100298

130. Ekelund C, Kopp TI, Tabor A, Petersen OB. The Danish fetal medicine database. Clin Epidemiol. 2016;8:479-483. doi:10.2147/ CLEP.S99477

131. Rygaard C. The Danish quality database for cervical cancer screening. Clin Epidemiol. 2016;8:655-660. doi:10.2147/CLEP.S99509

132. Jorgensen P, Lausten G, Becic Pedersen A. The Danish Sarcoma Database. Clin Epidemiol. 2016;8:685-690. doi:10.2147/CLEP.S99495

133. Jennum P, Larsen P, Cerqueira CS, Schmidt T, Tønnesen P. The Danish national database for obstructive sleep apnea. Clin Epidemiol. 2016;8:573-576. doi:10.2147/CLEP.S101969

134. Hansen S. The Danish neuro-oncology registry. Clin Epidemiol. 2016;8:629-632. doi:10.2147/CLEP.S99459

135. Andersson C, Flems C, Kesmodel US. The Danish national quality database for births. Clin Epidemiol. 2016;8:595-599. doi:10.2147/ CLEP.S99492

136. Nguyen-Nielsen M, Høyer S, Friis S, et al. The Danish prostate cancer database. Clin Epidemiol. 2016;8:649-653. doi:10.2147/ CLEP.S100256

137. Petersen A, Søgaard M, Mehnert F, et al. Danish renal cancer group database. Clin Epidemiol. 2016;8:725-729. doi:10.2147/CLEP. S106042
138. Bak M, Ibfelt EH, Stauffer Larsen T, et al. The Danish national chronic myeloid neoplasia registry. Clin Epidemiol. 2016;8:567572. doi:10.2147/CLEP.S99462

139. Groenvold M, Adsersen M, Hansen M. Danish palliative care database. Clin Epidemiol. 2016;8:637-643. doi:10.2147/CLEP. S99468

140. Jakobsen J, Öztürk B, Søgaard M. The Danish national penile cancer quality database. Clin Epidemiol. 2016;8:589-594. doi:10.2147/CLEP.S99513

141. Fristrup C, Detlefsen S, Hansen CP, Ladekarl M. Danish pancreatic cancer database. Clin Epidemiol. 2016;8:645-648. doi:10.2147/ CLEP.S99471

142. Jon Andersen M, Gromov K, Brix M, et al. The Danish Fracture Database can monitor quality of fracture-related surgery, surgeons experience level and extent of supervision. Dan Med J. 2014;61(6): A4839.

143. Hansen E, Larsson H, Nørgaard M, Thind P, Bjerggaard Jensen J. The Danish bladder cancer database. Clin Epidemiol. 2016;8:439 443. doi:10.2147/CLEP.S99491

144. Lassen A, Joergensen HS, Jørsboe HB, et al. The Danish database for acute and emergency hospital contacts. Clin Epidemiol. 2016;8:469-474. doi:10.2147/CLEP.S99505

145. Zwisler A-D, Rossau HK, Nakano A, et al. The Danish cardiac rehabilitation database. Clin Epidemiol. 2016;8:451-456. doi:10.2147/CLEP.S99502

146. Andersen LW, Østergaard JN, Antonsen S, et al. The Danish in-hospital cardiac arrest registry (DANARREST). Clin Epidemiol. 2019;11:397402. doi:10.2147/CLEP.S201074

147. Thomsen MK, Njor SH, Rasmussen M, et al. Validity of data in the Danish colorectal cancer screening database. Clin Epidemiol. 2017;9:105-111. doi:10.2147/CLEP.S124454

148. Frischknecht Christensen E, Berlac P, Nielsen H, Christiansen CF. The Danish quality database for prehospital emergency medical services. Clin Epidemiol. 2016;8:667-671. doi:10.2147/CLEP.S100919

149. Danish Health Data. Rapid response system database. Available from: www.danishhealthdata.com/find-health-data/Mobilt-akut-sys tem. Accessed February 1, 2019.

150. Larsen L, Jensen M, Larsen MD, et al. The Danish national registry for biological therapy in inflammatory bowel disease. Clin Epidemiol. 2016;8:607-612. doi:10.2147/CLEP.S99478

151. Backer V, Lykkegaard J, Bodtger U, Agertoft L, Korshoej L, Vaclavik Braüner E. The Danish national register for asthma. Clin Epidemiol. 2016;8:601-606. doi:10.2147/CLEP.S99494
Clinical Epidemiology

\section{Publish your work in this journal}

Clinical Epidemiology is an international, peer-reviewed, open access, online journal focusing on disease and drug epidemiology, identification of risk factors and screening procedures to develop optimal preventative initiatives and programs. Specific topics include: diagnosis, prognosis, treatment, screening, prevention, risk factor modification, systematic reviews, risk \& safety of medical interventions, epidemiology \& biostatistical methods, and evaluation of guidelines, translational medicine, health policies \& economic evaluations. The manuscript management system is completely online and includes a very quick and fair peer-review system, which is all easy to use. 